\title{
Climate response due to carbonaceous aerosols and aerosol-induced SST effects in NCAR community atmospheric model CAM3.5
}

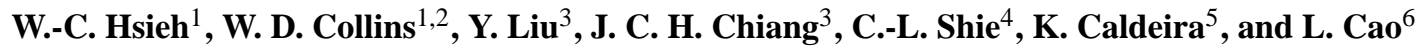 \\ ${ }^{1}$ Department of Earth and Planetary Science, University of California, Berkeley, California, USA \\ ${ }^{2}$ Lawrence Berkeley National Laboratory, Berkeley, California, USA \\ ${ }^{3}$ Department of Geography and Berkeley Atmospheric Sciences Center, University of California, Berkeley, CA, USA \\ ${ }^{4}$ The Joint Center for Earth Systems Technology, University of Maryland, Baltimore County, USA \\ ${ }^{5}$ Department of Global Ecology, Carnegie Institution, 260 Panama Street, Stanford, CA 94305, USA \\ ${ }^{6}$ Department of Earth Sciences, ZheJiang University, Hangzhou, ZheJiang, 310027, China
}

Correspondence to: W.-C. Hsieh (hsiehweichun@gmail.com)

Received: 23 October 2012 - Published in Atmos. Chem. Phys. Discuss.: 20 March 2013

Revised: 9 June 2013 - Accepted: 23 June 2013 - Published: 5 August 2013

\begin{abstract}
This study used the Community Atmospheric Model 3.5 (CAM3.5) to investigate the effects of carbonaceous aerosols on climate. The simulations include control runs with 3 times the mass of carbonaceous aerosols as compared to the model's default carbonaceous aerosol mass, as well as no-carbon runs in which carbonaceous aerosols were removed. The slab ocean model (SOM) and the fixed sea surface temperature (SST) were used to examine effects of ocean boundary conditions. Throughout this study, climate response induced by aerosol forcing was mainly analyzed in the following three terms: (1) aerosol radiative effects under fixed SST, (2) effects of aerosol-induced SST feedbacks, and (3) total effects including effects of aerosol forcing and SST feedbacks. The change of SST induced by aerosols has large impacts on distribution of climate response; the magnitudes in response patterns such as temperature, precipitation, zonal winds, mean meridional circulation, radiative fluxes, and cloud coverage are different between the SOM and fixed SST runs. Moreover, different spatial responses between the SOM and fixed SST runs can also be seen in some local areas. This implies the importance of SST feedbacks on simulated climate response. The aerosol dimming effects cause a cooling predicted at low layers near the surface in most carbonaceous aerosol source regions. The temperature response shows a warming (cooling) predicted in the north (south) high latitudes, suggesting that aerosol forcing can cause climate change in regions far away from its origins. Our simulation results show that direct and semidirect radiative forc-
\end{abstract}

ing due to carbonaceous aerosols decreases rainfall in the tropics. This implies that carbonaceous aerosols have possibly strong influence on weakening of the tropical circulation. Most changes in precipitation are negatively correlated with changes of radiative fluxes at the top of model. The changes in radiative fluxes at top of model are physically consistent with the response patterns in cloud fields. On global average, low-level cloud coverage increases, and mid- and high-level cloud coverage decreases in response to changes in radiative energy induced by aerosol forcing. An approximated moisture budget equation was analyzed in order to understand physical mechanism of precipitation changes induced by carbonaceous aerosols. Our results show that changes in tropical precipitation are mainly dominated are mainly dominated by the dynamic effect (i.e., vertical moisture transport carried by the perturbed flow).

\section{Introduction}

Carbonaceous aerosols increase largely from preindustrial time to present day (Ramanathan and Carmichael, 2008). These carbon aerosols can scatter sunlight and also absorb direct solar radiation. Both effects reduce UV and visible wavelength solar radiation received at the ground. This process is referred to as surface dimming, which leads to a cooling at the surface (Ramanathan et al., 2005). Moreover, absorption of solar energy by these carbon aerosols heats the 
atmosphere and subsequently affects atmospheric stability, which may induce changes in clouds, convection processes, and general circulations (Koch and Del Genio, 2010; Feingold et al., 2005). Depending on the net warming/cooling effects, aerosols can differently affect atmospheric circulations. The study by Allen and Sherwood (2010) has shown that a net warming effect is predicted with anthropogenic aerosols and a net cooling effect is simulated for natural aerosols. Their results demonstrated a nearly opposite change of circulations between these two aerosol scenarios.

It is known that the presence of black carbon (BC) can affect temperature at the surface and upper troposphere, and causes changes on clouds and precipitation. Chung and Seinfeld (2005) showed an increase in precipitation between 0 and $20^{\circ} \mathrm{N}$, a decrease in precipitation between 0 and $20^{\circ} \mathrm{S}$, and a northward shift of the Intertropical Convergence Zone (ITCZ) due to the direct radiative forcing of anthropogenic BC. The northward shift of ITCZ is also predicted in Wang (2004). Moreover, Menon et al. (2002) showed that absorbing $\mathrm{BC}$ aerosols can change large-scale circulations, affect hydrologic cycles, and have significant effects on regional climates. Ramanathan et al. (2005) used a coupled ocean-atmospheric model to understand the roles of absorbing aerosols in atmospheric brown clouds on the observed climate changes. They found that the radiative effects of aerosols can induce changes in meridional circulation and affect monsoon rainfall. Similar results were found in a study by Meehl et al. (2008), in which they showed that $\mathrm{BC}$ aerosols increase precipitation of premonsoon months (March-April-May) over India due to weakened latitudinal sea surface temperature gradient, and decrease Indian summer monsoon (June-September) as a result of reduced surface temperatures in the regions of the Bay of Bengal, the Arabian Sea, India, and the Himalayas. The study by Bollasina et al. (2011) also showed that the observed summertime drying in South Asia during the 1950-2000 period is mainly due to increasing anthropogenic aerosol emissions. Their results showed an imbalance of radiative energy between Northern and Southern Hemisphere due to asymmetry of aerosol distributions in the two hemispheres. The aerosol asymmetry then induces weakening of the tropical meridional overturning circulation.

Based on an atmosphere/mixed layer ocean general circulation model, Ming and Ramaswamy (2011) investigated changes in tropical circulations caused by anthropogenic aerosols. They showed that the forcing induced by aerosols weakens the Hadley cell in the Northern Hemisphere (NH) but strengthens that in the Southern Hemisphere (SH). The modified tropical circulations have significant impacts on the hydrological cycle. Another study by the aforementioned authors focused on how anthropogenic aerosols could affect boreal winter extratropical circulation (Ming et al., 2011). Based on the analysis of zonal mean response, their results showed a significant equatorward shift of the subtropical jet in the $\mathrm{NH}$ due to midlatitude aerosol cooling. It was also pointed out in their study that the induced anomalous diabatic heating over the tropical East Pacific caused by aerosol radiative forcings generates stationary Rossby waves that are closely linked to zonally asymmetrical response in midlatitudes.

The altitude where $\mathrm{BC}$ resides further complicates the assessment of effects of BC on climate. Ban-Weiss et al. (2011) used an atmospheric general circulation model coupled to a mixed layer ocean model to study the effects of BC at different altitudes on climate response. They have shown that BC at low (high) altitudes warmed (cooled) the surface and increased (decreased) precipitation. All of the abovementioned studies provide robust evidence that carbonaceous aerosols are important components in affecting regional climates and atmospheric circulations. However, the detailed processes on how aerosols interact with climate and how uncertain these assessments are, are still not clearly understood.

This study investigates climate response, including changes in temperatures, meridional mean circulations, horizontal winds, radiative fluxes, and clouds due to the direct and semidirect radiative effects of carbon aerosols. One of the objectives is to study how aerosol-induced sea surface temperature (SST) feedbacks affect climate. Section 2 describes the model and experiment design, followed by analysis of climate response in Sect. 3. Results and discussions are presented in Sect. 4, followed by the conclusion.

\section{Description of the model and experiments}

NCAR Community Atmospheric Model 3.5 (CAM3.5) is used in this study; a more detailed description of the model can be found in Collins et al. (2006). Here a brief summary of the overall model setting is provided. The horizontal resolution of the model is $1.9^{\circ}$ longitude by $2.5^{\circ}$ latitude and a total of 26 vertical layers is used, with the top layer centered at $3.54 \mathrm{hPa}$. All simulations are run with finite volume dynamic core and time step for model integration is $900 \mathrm{~s}$. For the ocean boundary conditions, we used both the fixed sea surface temperature (SST) and the slab ocean model (SOM) for each run.

Table 1 lists the eight experiments conducted in this study. All simulations include natural forcings such as solar variability and volcanic aerosols, and anthropogenic forcings such as greenhouse gases, ozone, and aerosols. A more detailed description of forcings can be found in Meehl et al. (2006). The aerosols are prescribed in our model, and there is no interaction between aerosols and meteorology. The prescribed aerosols include sulfate, sea salt, dust, and carbon aerosols, which consist of $\mathrm{BC}$ and organic carbon (OC). The present-day monthly aerosol distributions are produced from a three-dimensional aerosol assimilation model (Collins et al., 2002; Rasch et al., 2001) that comprises a model for atmospheric chemistry and transport (MATCH) (Rasch et al., 1997) and an assimilation of satellite retrievals 
of aerosol optical depth. The National Centers for Environmental Prediction (NCEP) reanalysis at the resolution of T63 (Kalnay, 1996) is used for MATCH integration. The satellite estimates of aerosol optical depth are obtained from the National Oceanic and Atmospheric Administration (NOAA) Pathfinder II dataset (Stowe et al., 1997). Sources of BC are determined based on the climatological inventories of aerosols produced by fossil fuel combustion and biomass burning, and all aerosols are treated as external mixtures (Collins et al., 2002).

For the control cases, all aerosol species are considered. For the cases without carbonaceous aerosols, experiment setup is the same as the control run except that carbonaceous aerosols were removed. Before running the SOM, a boundary dataset that includes information of mixed layer depth and surface fluxes is needed. Therefore, we first conducted a pair of experiments, FSSTc_CLIM and FSSTnc_CLIM, using the prescribed climatology of SST and ice data to generate outputs needed to initiate SOM runs. Thus, SST is fixed throughout the simulations. Lower case c/nc denotes simulation with/without carbonaceous aerosols. After building the boundary condition datasets needed for the SOM runs, a pair of SOM simulations SOMc and SOMnc were conducted to study climate response due to effects of aerosol forcing and aerosol-induced SST feedbacks in the SOM runs. In order to ensure that respective effects of aerosol forcing with or without SST feedbacks can be properly simulated and adequately identified, two more pairs of experiments with fixed SST (from two different datasets) are considered. FSSTc_SOMc and FSSTnc_SOMc use the SST outputs from SOMc, while FSSTc_SOMnc and FSSTnc_SOMnc use SST outputs from SOMnc (Table 1). As such, for either one of the above two pairs, the resultant difference between with and without carbon aerosol runs represents response of climate induced by effects of carbon aerosol forcing at the respective fixed SST. Likewise, effects of carbon aerosol forcing at the fixed SST climatology should be identified by the pair of FSSTc_CLIM and FSSTnc_CLIM. On the other hand, effects of aerosol-induced SST feedbacks on climate can be obtained from either one of the two following pairs of simulations (e.g., FSSTc_SOMc - FSSTc_SOMnc and FSSTnc_SOMc - FSSTnc_SOMnc) in which only SST initial condition is altered. Details of experiment analysis and quantified climate response are given in Sect. 3.

In the default CAM3.5, the computed atmospheric heating due to carbonaceous aerosols is much less than values from the literature (Allen and Sherwood, 2010; Chung et al., 2002). Thus, in our control simulations, we increased the default mass of carbonaceous aerosols by a factor of 3 . Figure 1 shows global distribution of carbonaceous aerosol optical depth. Large values of carbonaceous aerosol optical depth are in areas with high emissions such as Africa, South America, East Asia, India, and Europe. Figure 2 shows the seasonal average of zonal mean shortwave atmospheric absorption due to carbonaceous aerosols for a threefold increase in carbona-

\section{Daytime Average Carbon Optical Depth in visible band}

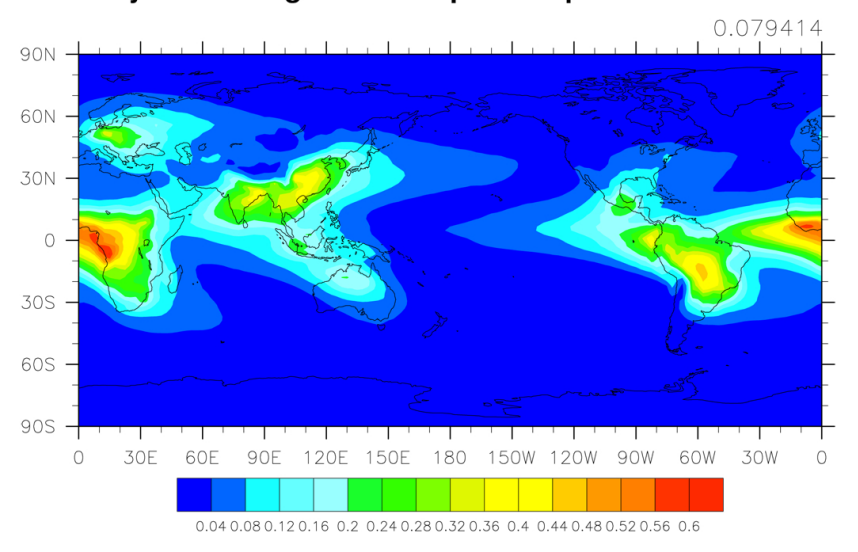

Fig. 1. Global distribution of carbonaceous aerosol optical depth. The mass of carbonaceous aerosols is increased by a factor of 3 as compared to the baseline mass in CAM3.5 to better represent atmospheric carbonaceous aerosols heating found from the literature.

ceous aerosol mass and baseline mass. The largest peak of absorption $\left(14 \mathrm{~W} \mathrm{~m}^{-2}\right)$ is around $10^{\circ} \mathrm{N}$ in DJF (DecemberJanuary-February), which is associated with carbonaceous aerosols in West Africa. The second largest absorption is in JJA (June-July-August) (about $11 \mathrm{~W} \mathrm{~m}^{-2}$ ), which is linked to carbonaceous aerosols near central Africa and South America. The third peak of absorption is at $40^{\circ} \mathrm{N}$, which is a result of carbon particle emission in Europe. The high concentrations of BC and OC during the dry season of MAM (MarchApril-May) in India and Asia are likely due to a weaker sink (i.e., precipitation scavenging rather than a higher emission compared to the summer monsoon season). In our model setup, only direct effects (scattering and absorption of radiation by aerosols) and semidirect effects (changes on cloud cover due to local warming caused by absorbing aerosols) of aerosols are included. The indirect effects (i.e., the changes of cloud properties (cloud droplet size, number, and precipitation) due to aerosols) are not considered.

The response of climate due to carbonaceous aerosols is obtained by comparing pairs of simulations of control and no-carbon runs. The annual mean changes due to with and without carbonaceous aerosols from various pairs of experiments are analyzed and presented. All simulations start on 1 September 2000 and run for $60 \mathrm{yr}$ for the fixed SST runs and $100 \mathrm{yr}$ for the SOM runs. For the fixed SST runs, the first $10 \mathrm{yr}$ are used as spin-up to allow model simulations to reach equilibrium. For the SOM runs, the spin-up time is the first $30 \mathrm{yr}$. Thus, we analyzed the last $50 \mathrm{yr}$ for the fixed SST runs and the last $70 \mathrm{yr}$ for the SOM runs. The results shown here are based on monthly average outputs. 
Table 1. Experiments conducted in this study. SOM stands for the slab ocean model run, followed by aerosol setting (lower case c/nc denotes simulation with/without carbonaceous aerosols). FSSTc_SOMc represents fixed sea surface temperature run with carbonaceous aerosols, where SST was obtained from SOMc (_SOMc). Similarly, FSSTnc_SOMc is the fixed sea surface temperature run without carbonaceous aerosols, where SST was obtained from SOMc._CLIM denotes climatology SST was used in the experiments.

\begin{tabular}{lllr}
\hline Cases & Aerosols & Ocean boundary condition & Simulation length \\
\hline SOMc & all aerosols & slab ocean model & $100 \mathrm{yr}$ \\
SOMnc & no carbon aerosols & slab ocean model & $100 \mathrm{yr}$ \\
FSSTc_SOMc & all aerosols & fixed SST from SOMc & $60 \mathrm{yr}$ \\
FSSTnc_SOMc & no carbon aerosols & fixed SST from SOMc & $60 \mathrm{yr}$ \\
FSSTc_SOMnc & all aerosols & fixed SST from SOMnc & $60 \mathrm{yr}$ \\
FSSTnc_SOMnc & no carbon aerosols & fixed SST from SOMnc & $60 \mathrm{yr}$ \\
FSSTc_CLIM & all aerosols & fixed SST from climatology & $60 \mathrm{yr}$ \\
FSSTnc_CLIM & no carbon aerosols & fixed SST from climatology & $60 \mathrm{yr}$ \\
\hline
\end{tabular}
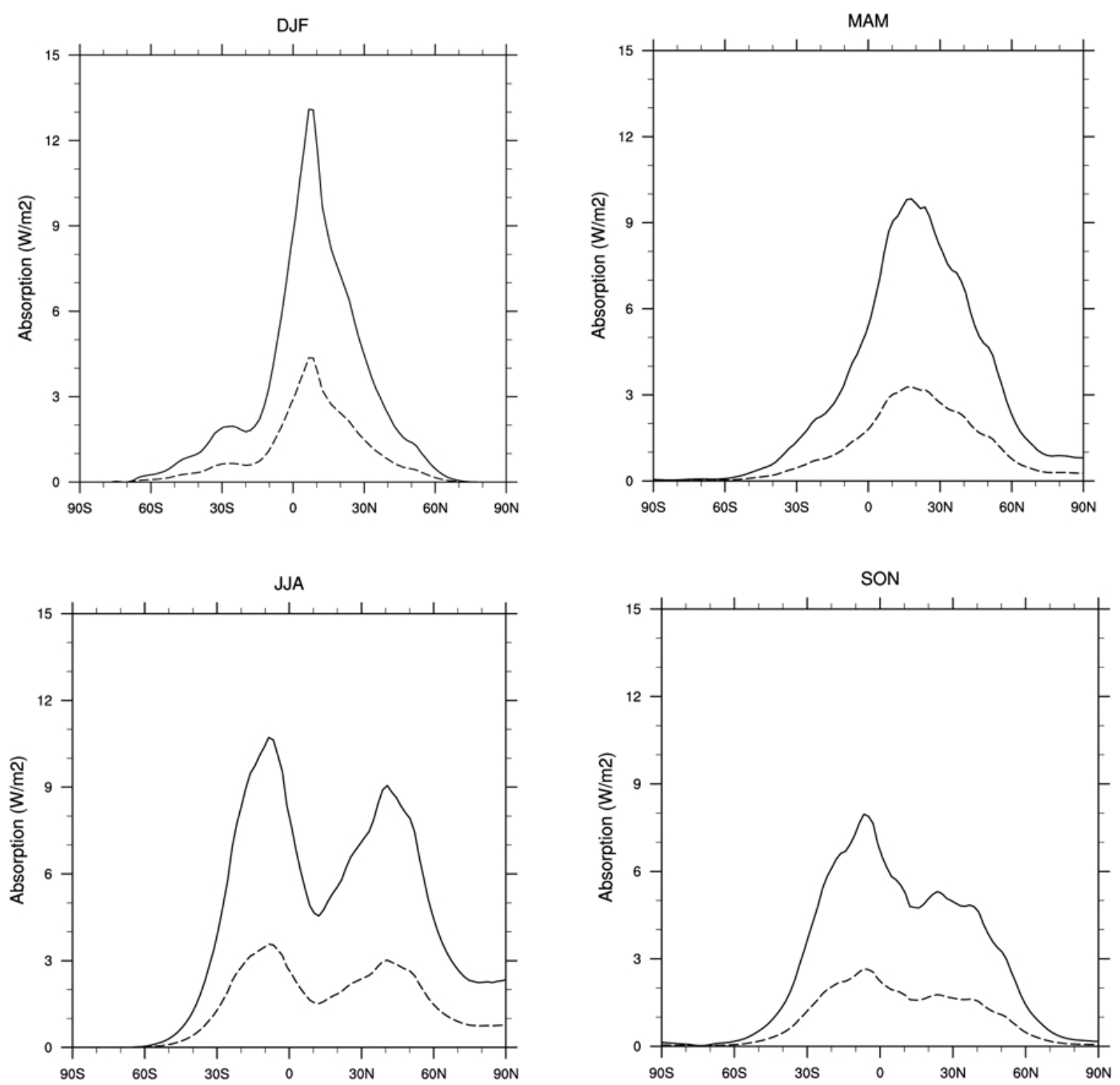

Fig. 2. Seasonal average of zonal mean shortwave atmospheric absorption $\left(\mathrm{W} \mathrm{m}^{-2}\right)$ due to carbonaceous aerosols. Solid line is for mass of carbonaceous aerosol increased by a factor of 3; the dashed line is the baseline mass in CAM3.5. 


\section{Analysis of climate response}

In this section, the methods used to analyze climatic response for a series of variables based on our eight simulations are introduced. Response of climate is calculated based on the following three effects: (1) total climatic effects including effects of aerosols and effects of SST feedbacks, (2) effects of carbonaceous aerosols, and (3) effects of SST feedbacks. Total climatic effects (Et) are calculated as the difference between the pair of SOM runs (i.e., control and no-carbon simulation):

$\mathrm{Et}=\mathrm{SOMc}-\mathrm{SOMnc}$,

As both FSSTc_SOMc and FSSTnc_SOMc experiments use the same (fixed) SST obtained from SOMc (Table 1), the resultant difference between this pair of runs (with and without carbonaceous aerosols) are thus considered due to "pure" effects of carbonaceous aerosols (Ea):

$\mathrm{Ea}=$ FSSTc_SOMc - FSSTnc_SOMc

Et (in Eq. 1) is considered including both "pure" aerosol effects and effects due to aerosol-induced SST feedbacks. Under a linear response assumption, the SST feedbacks (denoted as "Es") can be expressed as "Et minus Ea":

$\mathrm{Es}=\mathrm{SOMc}-\mathrm{SOMnc}-($ FSSTc_SOMc - FSSTnc_SOMc $)$

As mentioned in Sect. 2, a second pair of similar runs (i.e., FSSTc_SOMnc and FSSTnc_SOMnc) was also conducted, yet using a different fixed SST obtained from SOM_nc. It is intended to find out whether "pure" aerosol effects may vary at a different fixed SST. The associated carbon aerosol effect at a fixed SST from SOMnc can thus be considered as

Ea_SOMnc $=$ FSSTc_SOMnc - FSSTnc_SOMnc

In order to further validate a sole SST effect obtained from Eq. (3), a second approach for acquiring this sole SST effect (denoted as "Es_nc") is to subtract FSSTnc_SOMnc from FSSTnc_SOMc; that is, a pair of runs only differ in SST.

Es_nc $=$ FSSTnc_SOMc - FSSTnc_SOMnc

Similarly, another SST effect can also be calculated based on a pair of runs with different SST but both with prescribed carbon aerosols:

Es_c $=$ FSSTc_SOMc - FSSTc_SOMnc

As mentioned in Sect. 2, FSSTc_CLIM and FSSTnc_CLIM, using the fixed climatology of SST, were first conducted to generate outputs needed for initiating SOM runs. In addition to Ea and Ea_SOMnc, a third expression of aerosol effect (Ea_CLIM) is also calculated as

Ea_CLIM $=$ FSSTc_CLIM - FSSTnc_CLIM
Et: SST

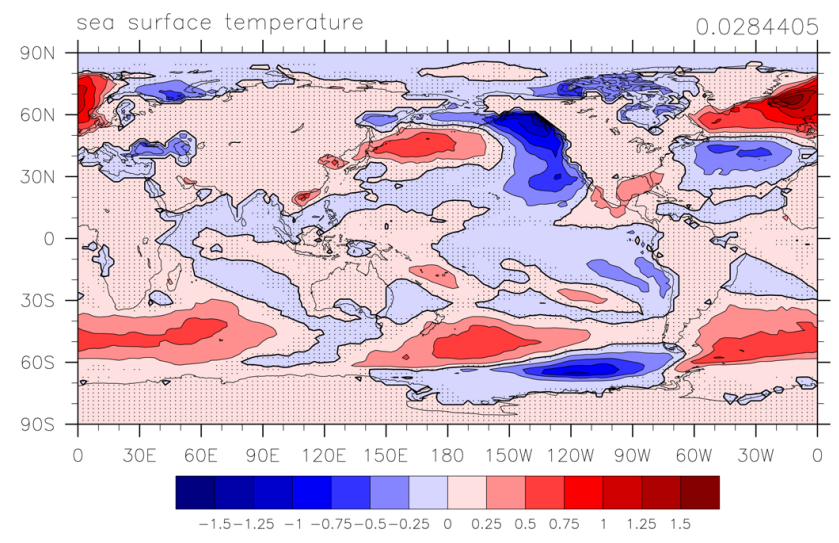

Fig. 3. The change in SST between SOM_c and SOM_nc experiment. The dotted areas are changes that are not statistically significant at the $95 \%$ confidence level.

A list of climate effects expressed by Eqs. (1)-(7) is summarized in Table 2. We will analyze climate response induced solely by carbonaceous aerosol forcing (Ea), interactive SST feedbacks (Es), and total effect (Et) including Ea and Es. Note again that interactive SST feedback is induced by radiative effects of carbon aerosols and change of SST is calculated based on the pair of SOM runs with and without carbon aerosols.

\section{Results}

\subsection{Comparison of climate response}

In this section, we analyzed seven climatic effects defined in Table 2 to study the response of climate induced by direct radiative aerosol effects (Ea, Ea_SOMnc, and Ea_CLIM), SST effects caused by aerosols (Es, Es_nc, and Es_c), and the total effects from direct radiative aerosol and SST effects (Et). Figure 3 shows the SST difference based on the pair of SOM runs with and without carbon aerosols. The analysis for surface air temperature is shown in Fig. 4. The small black dots represent the changes that are not significant at $95 \%$ confidence interval, which was calculated based on the Student's $t$ test (Zwiers and von Storch, 1995). The whole dataset comprises yearly averaged results from a total of $50 \mathrm{yr}$ (the fixed SST runs) and $70 \mathrm{yr}$ (the SOM runs).

The induced surface air temperature changes in Et are more pronounced than the changes resulting from direct radiative aerosol effects (Ea, Ea_SOMnc, and Ea_CLIM). There is an increase in tropospheric meridional temperature gradient near the north of India for all three Ea plots, indicating that this feature is induced solely by aerosol forcing, with no SST feedbacks involved. This increased meridional temperature gradient can affect monsoon and precipitation in India, which has been discussed extensively in the literature 
Table 2. Equation of climate effect analysis. Experiment notation is listed in Table 1, and details of experiment design for different simulations are described in Sect. 2.

\begin{tabular}{lc}
\hline Equation of climate effect analysis & Equation number \\
\hline Et $=$ SOMc - SOMnc & $(1)$ \\
Ea $=$ FSSTc_SOMc - FSSTnc_SOMc & $(2)$ \\
Es $=$ SOMc - SOMnc - (FSSTc_SOMc - FSSTnc_SOMc) & $(3)$ \\
Ea_SOMnc $=$ FSSTc_SOMnc - FSSTnc_SOMnc & $(4)$ \\
Es_nc $=$ FSSTnc_SOMc - FSSTnc_SOMnc & $(5)$ \\
Es_c $=$ FSSTc_SOMc - FSSTc_SOMnc & $(6)$ \\
Ea_CLIM $=$ FSSTc_CLIM - FSSTnc_CLIM & $(7)$ \\
\hline
\end{tabular}

(Meehl et al., 2008; Ramanathan et al., 2005). To study effects of SST on climate, two additional runs (FSSTc_SOMnc and FSSTnc_SOMnc, Table 1) that use SST output from the SOM run without carbon aerosols were conducted. The similarity among Es, Es_nc, and Es_c indicates that approximating Es (the response of climate to the SST change induced by aerosols) by "Et $-\mathrm{Ea}$ " is a legitimate metric.

The dimming effect of carbonaceous particles leads to cooling in most carbonaceous aerosol source regions such as West and southern Africa, India, East Asia, South America, and northern Australia for both Ea and Et. However, in the SOM run (Et), cooling is also simulated in the central Atlantic and most areas of North America, including its west coast. The changes of surface air temperatures resulting from inhomogeneous aerosol forcing have larger variations in mid- to high latitudes compared to the tropics, where the response is smaller because internal gravity waves in the tropics can efficiently remove horizontal temperature gradients. However, the thermal forcing in midlatitudes is more likely constrained in the local areas because the controlling dynamic mechanism is different from that of tropics (Ming and Ramaswamy, 2011).

A strong warming in the eastern part of Canada, the North Atlantic, and the Southern Hemisphere (SH) mid- to high latitudes from 30 to $70^{\circ} \mathrm{S}$ is shown in Et and Es. This phenomenon is a result of atmosphere-ocean interaction that is driven by the radiative effect of carbon aerosols. Through the change in SST, the general atmospheric circulations were modified, which can induce temperature response in these remote regions. Therefore, the effects of carbon aerosols not only affect local climates where particles are emitted but also influence those in remote areas far away from particle sources (Chung and Seinfeld, 2005). Note that the study by Meehl et al. (2008) investigated the effects of BC aerosols on Indian monsoon and they have shown that, during the season of MAM, there is a decrease in surface air temperature in areas of India, the Bay of Bengal, the Arabian Sea, and South Asia including Bhutan, Bangladesh, Myanmar, Thailand, Laos, Vietnam, and Cambodia. Our simulation is consistent with Meehl et al. (2008), and also shows a decline in surface air temperature in these areas. Table 3 summarized the global average response for a list of climate variables an- alyzed based on Et, Ea, and Es. A slight warming near the surface is simulated in both ocean boundary condition runs (i.e., $0.038 \mathrm{~K}$ for $\mathrm{Et}$ and $0.02 \mathrm{~K}$ for $\mathrm{Ea}$ ).

The analysis of climate response for precipitation is shown in Fig. 5. Change in precipitation in Ea is qualitatively similar to Et, but with a smaller magnitude. Similar to analysis of surface air temperature, the precipitation response pattern in Es is also close to Es_nc and Es_c. This result again confirms that using the metric Es to represent effects of aerosolinduced SST effect in the SOM runs is robust. Therefore, only analysis of Et, Ea, and Es are shown in the following sections. Note that, as compared to Es_c, a slightly large precipitation change was found in Es_nc, where carbon aerosols are not included in the experiments.

An increase in precipitation due to aerosol forcing is simulated in several regions, including India, Pakistan, Afghanistan, Iran, parts of Iraq, and Saudi Arabia. The positive changes in precipitation range from 4 to $40 \%$, which are also simulated near the west of Africa around $0-30^{\circ} \mathrm{S}$. For the SOM run, a striking feature is the decrease in precipitation in the East Pacific near $10-20^{\circ} \mathrm{N}$ that extends to southwest of the United States. The decreased precipitation in the East Pacific near $10-20^{\circ} \mathrm{N}$ was not seen in the fixed SST run. Also, the area/degree of decreased precipitation in the South Pacific around 0 to $30^{\circ} \mathrm{S}$ and 180 to $90^{\circ} \mathrm{W}$ is much broader/larger in the Et than that in the Ea. This implies the importance of ocean boundary condition on the simulated precipitation response distribution due to the external forcing caused by carbon aerosols.

Meehl et al. (2008) studied the effects of BC on the Indian monsoon. Based on their model experiments, they have concluded that the observed trends of decreasing precipitation during summer monsoon season over parts of India, Bangladesh, Burma, and Thailand are largely related to BC aerosols. Our results show an increase of JJA precipitation in central to northern India, Bangladesh, and the north of the Bay of Bengal, which is opposite to their results. The possible reasons for the discrepancy may be that Meehl et al. (2008) only included BC, while this study is about total carbonaceous aerosols, the former introduces a strong atmospheric heating and a surface cooling in close magnitude, the latter perhaps introduces a much higher cooling 

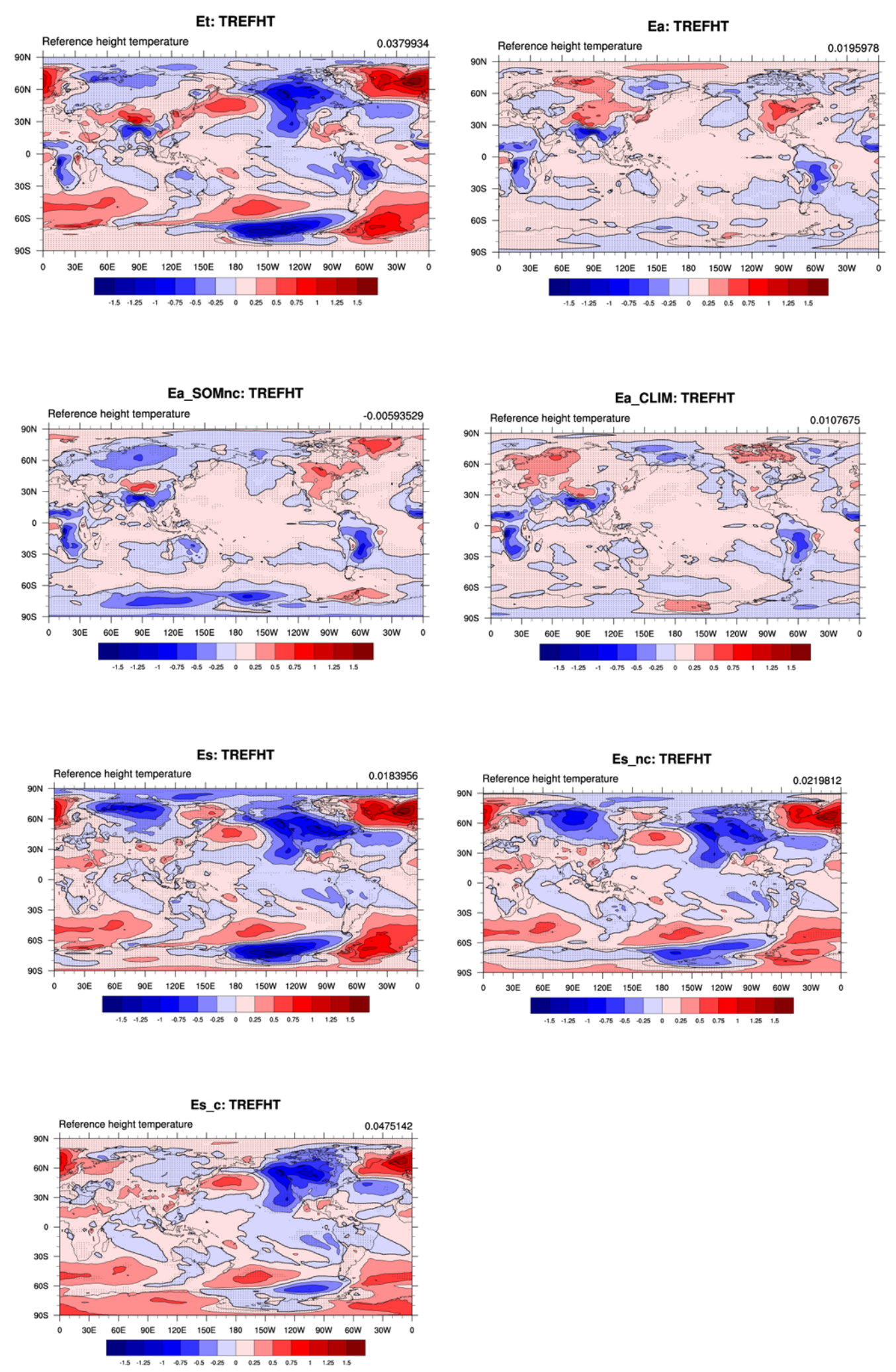

Fig. 4. Analysis of total (Et), aerosol (Ea,Ea_SOMnc, and Ea_CLIM), and SST (Es, Es_nc, and Es_c) effect for temperature at the reference height (about $2 \mathrm{~m}$ above the surface). Dotted areas are changes that are not statistically significant at $95 \%$ confidence level. All climatic analyses are defined in Table 2. Global mean value is shown on the upper right corner. Unit is $\mathrm{K}$. 


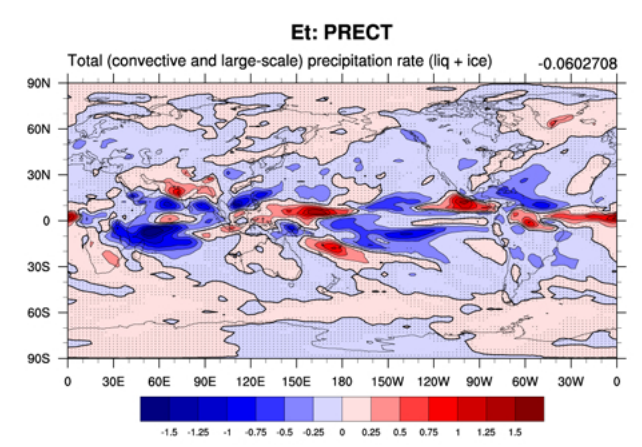

Ea_SOMnc: PRECT

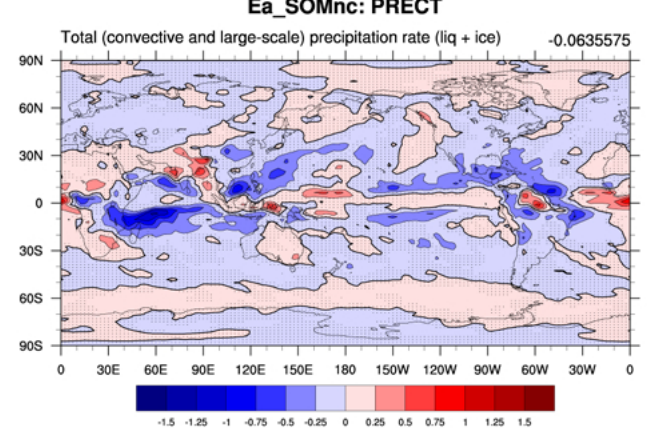

Es: PRECT
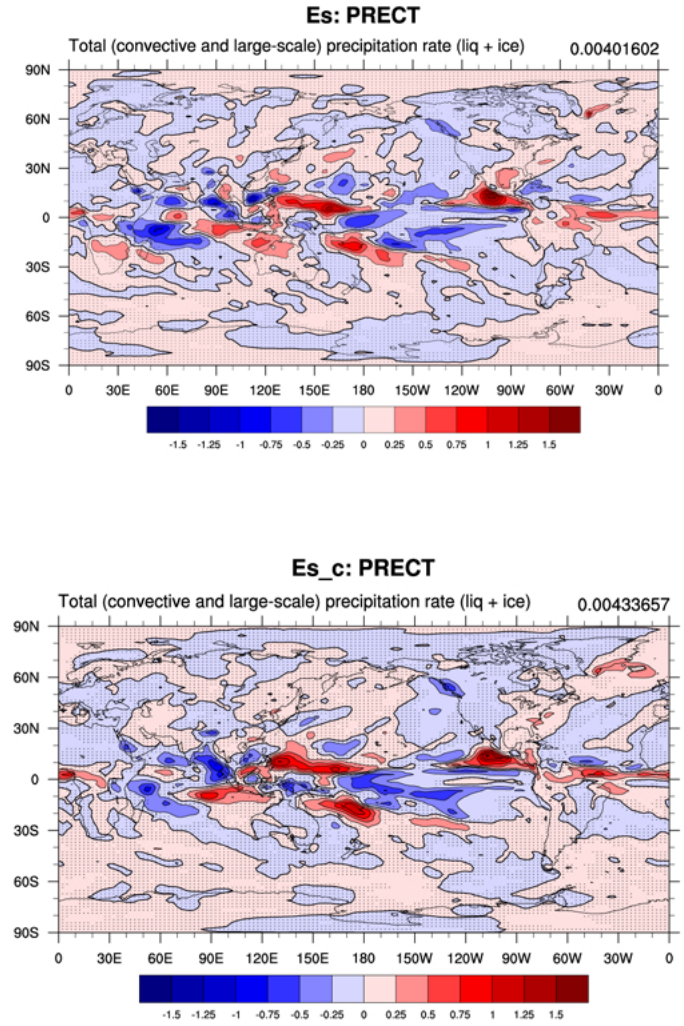

Fig. 5. Same as Fig. 4 but for precipitation. Unit is $\mathrm{mm} \mathrm{day}^{-1}$.

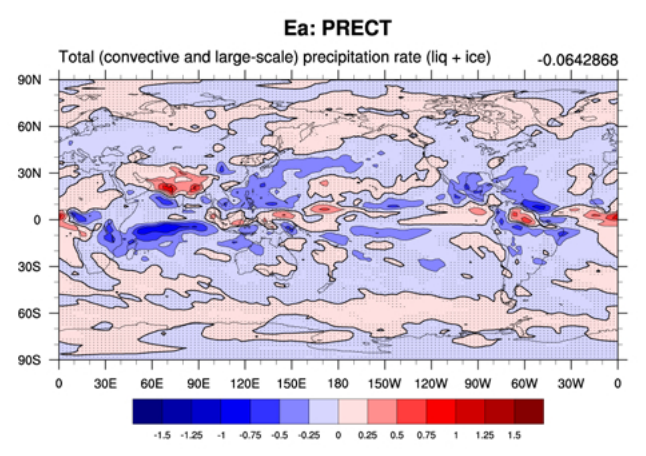

Ea_CLIM: PRECT

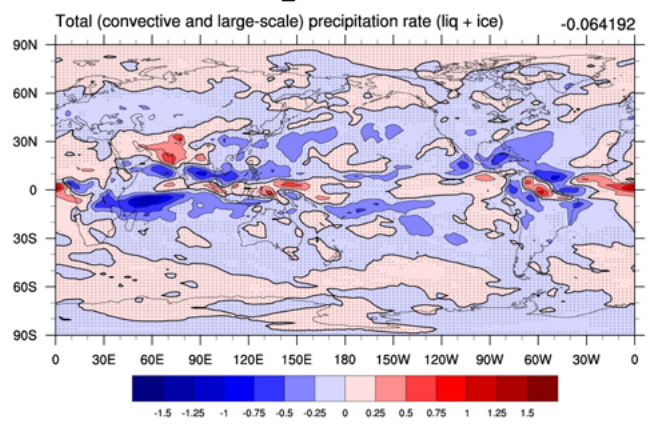

Es_nc: PRECT

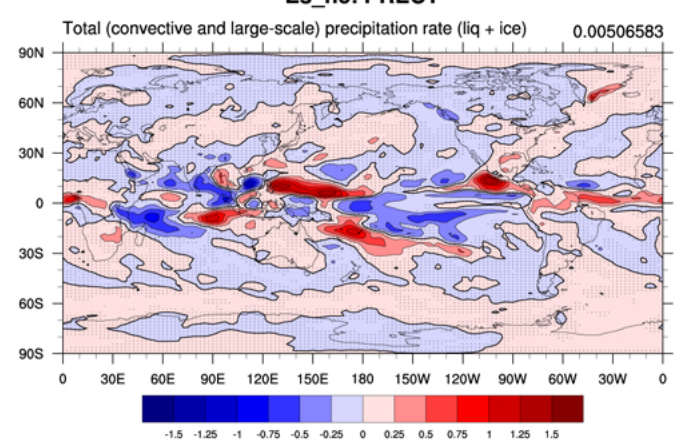


Table 3. The annual mean global average $\mathrm{Et}, \mathrm{Ea}, \mathrm{Es}, \mathrm{Et}^{2}, \mathrm{Ea}^{2}$, and $\mathrm{Es}^{2}$ for a list of climate variables. Units in parentheses are for $\mathrm{Et}$, Ea, and Es analysis. Corresponding unit for $\mathrm{Et}^{2}\left(\right.$ or $\mathrm{Ea}^{2}, \mathrm{Es}^{2}$ ) is square of $\mathrm{Et}$ (or $\mathrm{Ea}$, Es) unit.

\begin{tabular}{|c|c|c|c|c|c|c|}
\hline Variable & Et & $\mathrm{Ea}$ & Es & $\mathrm{Et}^{2}$ & $\mathrm{Ea}^{2}$ & $\mathrm{Es}^{2}$ \\
\hline Surface air temperature $(\mathrm{K})$ & 0.038 & 0.020 & 0.018 & 0.69 & 0.27 & 0.95 \\
\hline Surface temperature $(\mathrm{K})$ & -0.004 & -0.021 & 0.016 & 0.73 & 0.27 & 0.98 \\
\hline Total cloud cover $(\%)$ & 0.198 & 0.091 & 0.107 & 17.36 & 12.83 & 27.78 \\
\hline Low-level cloud cover (\%) & 0.539 & 0.455 & 0.084 & 12.25 & 7.93 & 18.04 \\
\hline Mid-level cloud cover $(\%)$ & -0.392 & -0.399 & 0.007 & 12.25 & 9.16 & 20.30 \\
\hline High-level cloud cover $(\%)$ & -0.175 & -0.306 & 0.131 & 21.05 & 15.30 & 33.66 \\
\hline Surface sensible heat flux $\left(\mathrm{Wm}^{-2}\right)$ & -1.231 & -1.163 & -0.068 & 17.82 & 15.24 & 18.19 \\
\hline Surface latent heat flux $\left(\mathrm{Wm}^{-2}\right)$ & -1.745 & -1.862 & 0.117 & 48.93 & 59.19 & 87.77 \\
\hline Sea level pressure $(\mathrm{hPa})$ & 1.988 & 1.432 & 0.557 & 25968.05 & 22868.56 & 49343.16 \\
\hline Clear-sky net solar flux at surface $\left(\mathrm{Wm}^{-2}\right)$ & -5.480 & -5.478 & -0.002 & 79.25 & 70.16 & 12.04 \\
\hline Net solar flux at surface $\left(\mathrm{Wm}^{-2}\right)$ & -4.118 & -3.923 & -0.195 & 101.99 & 82.29 & 96.63 \\
\hline Clear-sky net longwave flux at surface $\left(\mathrm{Wm}^{-2}\right)$ & -0.706 & -0.646 & -0.060 & 6.92 & 4.88 & 8.72 \\
\hline Net longwave flux at surface $\left(\mathrm{Wm}^{-2}\right)$ & -0.780 & -0.664 & -0.116 & 16.10 & 11.50 & 23.25 \\
\hline Clear-sky net solar flux at top of model $\left(\mathrm{Wm}^{-2}\right)$ & -1.152 & -1.170 & 0.018 & 13.71 & 6.24 & 10.96 \\
\hline Net solar flux at top of model $\left(\mathrm{Wm}^{-2}\right)$ & 0.209 & 0.370 & -0.161 & 49.02 & 36.75 & 79.02 \\
\hline Clear-sky net longwave flux at top of model $\left(\mathrm{Wm}^{-2}\right)$ & 0.263 & 0.230 & 0.033 & 4.36 & 2.41 & 6.21 \\
\hline Net longwave flux at top of model $\left(\mathrm{Wm}^{-2}\right)$ & 0.559 & 0.604 & -0.045 & 32.93 & 23.05 & 50.26 \\
\hline Total precipitation rate $\left(\mathrm{mm} \mathrm{day}^{-1}\right)$ & -0.060 & -0.064 & 0.004 & 0.55 & 0.35 & 0.85 \\
\hline
\end{tabular}

effect compared to the atmospheric heating in terms of absolute magnitude. Another study by Lau and Kim (2006) has pointed out that absorbing aerosols over the Indo-Gangetic Basin in northern India will induce rising air motions over the southern slope of the Tibetan Plateau. As the convection is limited in central India during MAM due to surface cooling caused by particle dimming effects, more moist warm air is drawn into the rising air over northern India, which generates deep convection and enhances local Hadley circulation, causing an increase of rainfall over northern India and a decrease of rainfall in the northern Indian Ocean. Our results on precipitation change in JJA are similar to Lau and Kim (2006). Both ocean SST runs predict $<20 \%$ increase in precipitation over northern India and decreased rainfall over the northern and parts of the southern Indian Ocean.

When analyzing global mean climate response, we found that the value of globally averaged $\mathrm{Ea}$ is greater than Es for most climate variables listed in Table 3 . However, spatial distributions of response patterns in Figs. 4 and 5 show that magnitudes of response in Es are larger than Ea in most of the regions. Therefore, an additional analysis involving variances of Et, Ea, and Es that account for (regional) "absolute changes" (originally positive or negative) is also conducted. The time series of global mean annually averaged low-level cloud coverage in Et, Ea, Es, and their variances for $60 \mathrm{yr}$ are analyzed, and we found the variance $\mathrm{Es}^{2}$ has the largest averaged response magnitudes (not shown). The smaller Es than Ea shown in Table 3 is mainly due to cancelations of positive and negative response as a result of the global average. The corresponding variance analysis of $\mathrm{Et}^{2}$,
$\mathrm{Ea}^{2}$, and $\mathrm{Es}^{2}$ summarized in Table 3 confirms that except for the clear-sky net solar flux at the surface, all other variables possess a greater global mean variance of Es than that of Ea. This implies that the aerosol-induced SST change has generally caused a greater climate response (could be positive or negative, though) among various regions than the sole aerosol effect does. Nonetheless, such SST impact revealed in this study may still be regarded as an effect "induced" by aerosols.

\subsection{Overall climate response}

Figure 6 shows the Et, Ea, and Es analysis of annual average data for sea level pressure (SLP) and geopotential height at $500 \mathrm{mb}$ (Z500). The changes in $850 \mathrm{mb}$ horizontal winds are also plotted as vector fields in the SLP plot, and the changes in $500 \mathrm{mb}$ horizontal winds are included in Z500 plots. An increase in SLP in the central Pacific Ocean is seen in both ocean SST simulations. This increased SLP is associated with clockwise wind changes at $850 \mathrm{hPa}$. In high-latitude regions around $60-90^{\circ} \mathrm{N}$, the fixed SST run shows a decreased SLP. However, the SOM run shows an average increase of SLP in this latitude band. The radiative forcing due to carbon aerosols also influences the trade winds. There is an increase of easterly near the central to West Pacific around the Equator and a decrease of easterly at the East Pacific near $0^{\circ}$. The Es analysis also shows that induced changes in easterlies have the same sign of changes as Ea. Thus the feature of easterly change induced by carbon aerosols is enhanced by interactive SST effect. The response in $850 \mathrm{mb}$ horizontal winds in the tropics is highly related to convective mixing. 

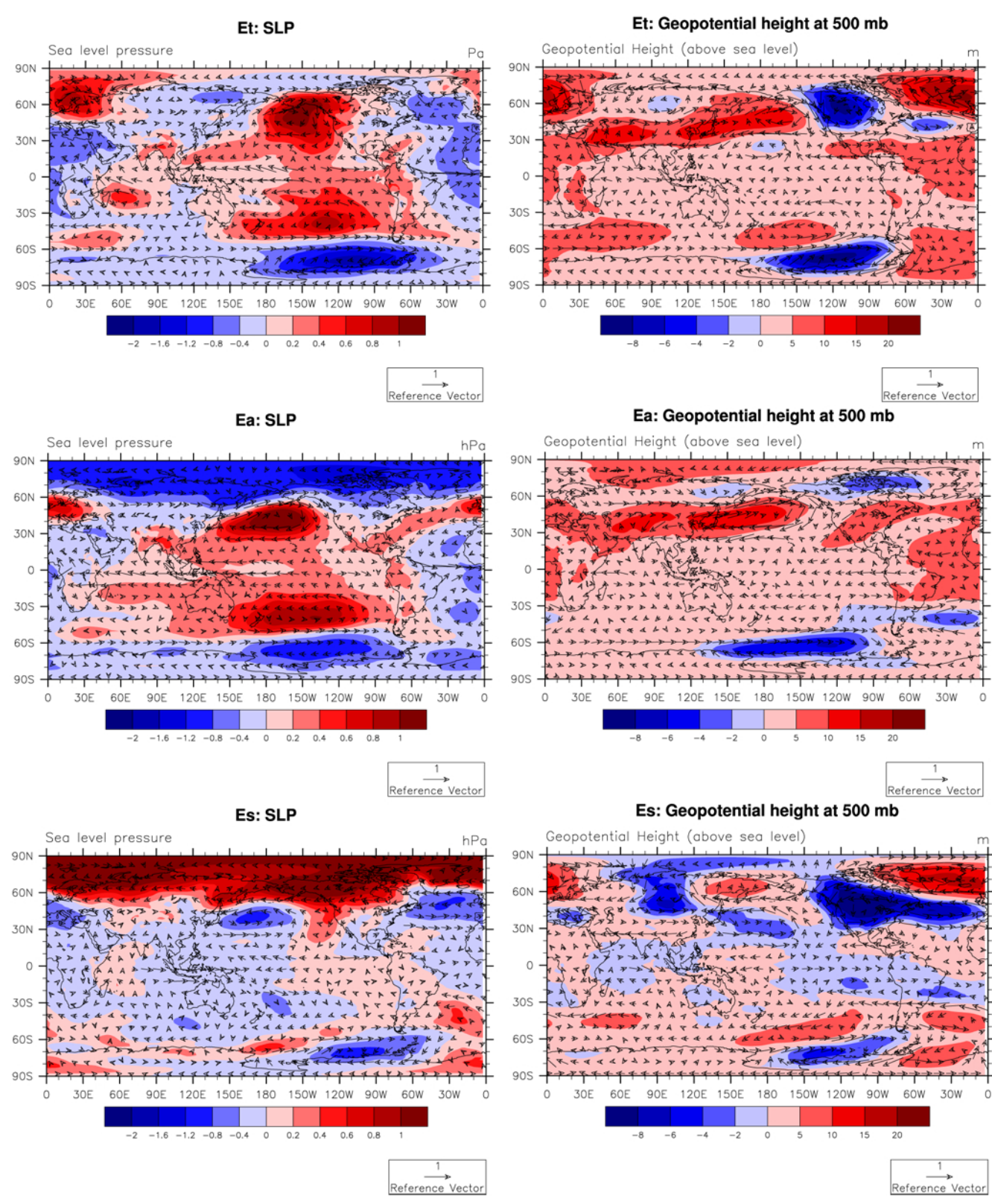

Es: Geopotential height at $500 \mathrm{mb}$

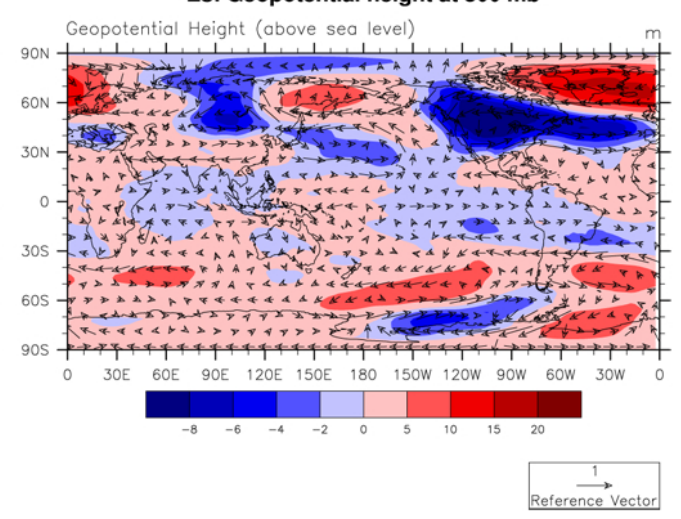

Fig. 6. Changes in SLP and horizontal winds at $850 \mathrm{mb}$ (left column) and changes in geopotential height and horizontal winds at $500 \mathrm{mb}$ (right column). The unit is $\mathrm{hPa}$ for SLP, $\mathrm{ms}^{-1}$ for horizontal winds and $\mathrm{m}$ for geopotential height.

For example, the mixing process causes vertical propagation of elevated momentum from higher altitudes to the surface, which changes the winds near the surface (Chiang et al., 2001).

Figure 7 shows the vertical profiles of annually averaged changes in temperature and vertical velocity (omega). The aerosol forcing causes a warming in most of the troposphere (Ea). A slight cooling in the upper troposphere to lower stratosphere near the $\mathrm{NH}$ polar region was predicted in the fixed SST runs. With the SOM runs, there was a strong warming in this region. The magnitude of cooling in the SH polar region is greater in the SOM than in the fixed SST run. The temperature change in the upper atmosphere between Et and Ea is in the opposite direction (Fig. 7), which is associated with large warming seen in Es in this area.

The omega fields stand for vertical velocities computed at the pressure coordinate; upward/downward motions correspond to negative/positive values. Both SOM and fixed SST runs show an area of negative omega change centered around $20^{\circ} \mathrm{N}$ from 850 to $150 \mathrm{mb}$, and positive omega change at $10^{\circ} \mathrm{S}$. As compared to the differences from the fixed SST run, the SOM run predicts a larger and broader positive omega change at $10^{\circ} \mathrm{S}$. A negative omega change is predicted near the Equator in the $\mathrm{NH}$, which is associated with 
an enhancement in upward motions and an increase in precipitation. The peak of rainfall increase in this region is shown in the zonal mean plot (Fig. 8). Similarly, the minimum of precipitation decrease around $5^{\circ} \mathrm{S}$ is consistent with the positive pressure velocity changes (Fig. 7) where reduced rising motions are simulated.

\subsection{Zonal average changes}

Figure 8 shows the changes in zonally averaged reference height temperature (i.e, surface air temperature about $2 \mathrm{~m}$ above the surface); precipitation; SLP; vertically integrated low-, mid-, and high-level cloud coverage; surface sensible heat flux; and surface latent heat flux for Et, Ea, and Es. The induced change in surface air temperature has opposite sign near polar regions in both hemispheres between two ocean SST runs. In the NH polar region, the SOM run predicts a cooling around $-0.2 \mathrm{~K}$, but in the fixed SST, the zonal mean change is close to $0.2 \mathrm{~K}$. The opposite response between two ocean runs for surface air temperature is also seen in the South Pole, where a warming of $\sim 0.2 \mathrm{~K}$ is predicted in the SOM but a cooling of $\sim-0.15 \mathrm{~K}$ is simulated in the fixed SST run. The zonal mean precipitation changes show the largest decrease of precipitation is around $6^{\circ} \mathrm{S}$, where the decrease is $\sim-0.35 \mathrm{~mm} \mathrm{day}^{-1}$ for the SOM and $-0.25 \mathrm{~mm} \mathrm{day}^{-1}$ for the fixed SST run. Both ocean SST runs show an increase of precipitation near the Equator $\sim 2^{\circ} \mathrm{N}$. The pattern of precipitation changes is largely related to changes in the mean meridional circulation and tropical convection that are induced by interhemispheric temperature gradient caused by inhomogeneous radiative forcing of carbon aerosols.

The SOM runs simulate a change of $\sim-0.6 \%$ in lowlevel cloud coverage at $40-50^{\circ} \mathrm{S}$ and an increase of $\sim 0.8 \%$ at near $65^{\circ} \mathrm{S}$, however, no obvious zonal mean change is predicted in the fixed SST runs. Most latitude zones show an increased low-level cloud coverage as a result of aerosolinduced SST feedback. The changes of mid- and high-level cloud coverage are consistent with changes in precipitation, as the largest reduction of mid- and high-level cloud coverage is also seen at $\sim 8^{\circ} \mathrm{S}$ for both ocean runs. On global average, an increase of low-level cloud coverage by $0.53 \%$ and a decrease of $-0.39 \%$ and $-0.18 \%$ for mid-level and highlevel cloud coverage were simulated as a response to aerosol forcing and its induced SST effects based on the SOM runs.

The zonal mean changes of sensible heat and latent heat flux are similar between two ocean SST runs, except that at $\sim$ $50^{\circ} \mathrm{S}$, a positive change of zonal mean latent heat flux about $1.7 \mathrm{Wm}^{-2}$ is predicted in the SOM runs but only $0.2 \mathrm{Wm}^{-2}$ is simulated in the fixed SST runs. The zonal average changes for latent and sensible heat fluxes in most latitudes are negative because less solar energy reaches the ground due to scattering and absorption caused by carbon aerosols (Wang, 2004).

\subsection{Response of mean meridional circulation}

Figure 9 shows Et, Ea, and Es analysis of mean meridional circulation (MMC) for DJF, JJA, and ANN (Annual mean). The unit of MMC is $10^{9} \mathrm{~kg} \mathrm{~s}^{-1}$. In DJF, there is a weakening of MMC near the equator and the degree of weakening is larger in the SOM runs than in the fixed SST runs. The study of Allen and Sherwood (2010) showed that, as compared to simulation based on natural aerosol forcing, anthropogenic aerosol forcing has the effect of weakening MMC. The computed radiative aerosol forcing in their study is based on aerosol optical depth summed from BC, OC, sulfate, sea salt, and dust. Our results of MMC response due to carbonaceous aerosols are similar to Allen and Sherwood (2010), and also show a weakening of MMC in DJF in the SOM run. In JJA, positive changes of streamline functions around $30^{\circ} \mathrm{N}$ indicate a strengthening of circulation, and the area of strengthening is slightly broader in Ea than Et. Note that the study of Chung and Seinfeld (2005) also showed that during DJF, the Hadley cell circulation is weakened but strengthened again during JJA as a result of semidirect BC radiative forcing. For ANN, changes of MMC, both ocean SST runs show a strengthening of $\mathrm{MMC}$ at $30^{\circ} \mathrm{N}$. However, for the Hadley cell near 15 to $30^{\circ} \mathrm{S}$, the SOM runs show a weakening of MMC, but a slight enhancement at lower model layers is shown otherwise in the fixed SST runs. An area of negative change of $\mathrm{MMC}$ across the equator near $10^{\circ} \mathrm{S}$ to $20^{\circ} \mathrm{N}$ is shown in both Et and Ea. These changes of MMC induced by aerosol forcing and the SST feedbacks have the effect of modifying energy transport processes, and affect regional climates and atmospheric circulations.

To further quantify Hadley cell changes, we compute the width of Hadley circulations using the metric based on Johanson and Fu (2009). Johanson and Fu (2009) defined the total width of the Hadley cell as the distance between the latitudes in each hemisphere where meridional mass flux at $500 \mathrm{hPa}$ is equal to zero. Based on the seasonally averaged outputs of MMC, we use the bisection method to find the zero MMC at $500 \mathrm{hPa}$ for $\mathrm{NH}$ and SH latitude. Tables 4 and 5 show the latitudes of the zero meridional mass flux at $500 \mathrm{hPa}$ for both hemispheres, the width of the Hadley cell and the change of the width between control and no-carbon runs. The predicted change in the Hadley cell width has the same sign in two ocean boundary condition runs for most seasons except JJA, where the SOM runs predicted an increase of $0.25^{\circ}$ but a decrease of $-0.23^{\circ}$ was simulated in the fixed SST runs. In DJF and MAM, the absolute magnitude of the Hadley cell width change is larger in the SOM than the fixed SST runs. However, the maximum change $\left(0.33^{\circ}\right)$ is seen in SON (September-October-November) with fixed SST runs. In DJF, both fixed SST and the SOM runs show a slightly decreased width change of $\sim-0.1^{\circ}$. For the annual average calculation, the Hadley cell width change based on with and without carbon aerosol simulations increases in both SOM runs and fixed SST runs. Several studies have pointed out that 
Table 4. The SH and NH latitudes of zero meridional mass flux at $500 \mathrm{hPa}$, the width of the Hadley cell, and change of the width between control and no-carbon runs. Results are from the SOM runs.

\begin{tabular}{llrllr}
\hline Season & Simulation & SH & NH & Width & Width change \\
\hline \multirow{2}{*}{ DJF } & SOMc & -37.2365 & 31.3202 & 68.5567 & -0.096 \\
& SOMnc & -37.223 & 31.4297 & 68.6527 & \\
\multirow{2}{*}{ MAM } & SOMc & -34.3116 & 29.3196 & 63.6312 & 0.2806 \\
& SOMnc & -34.5463 & 28.8043 & 63.3506 & \\
JJA & SOMc & -30.3387 & 38.5929 & 68.9316 & 0.2539 \\
& SOMnc & -30.243 & 38.4347 & 68.6777 & \\
SON & SOMc & -31.915 & 38.0096 & 69.9246 & 0.2246 \\
& SOMnc & -31.666 & 38.034 & 69.7 & \\
ANN & SOMc & -32.9901 & 33.3743 & 66.3644 & 0.1379 \\
& SOMnc & -33.0058 & 33.2207 & 66.2265 & \\
\hline
\end{tabular}

Table 5. Same as Table 4 but for the fixed SST runs.

\begin{tabular}{llrllr}
\hline \multirow{2}{*}{ Season } & Simulation & SH & NH & Width & Width change \\
\hline \multirow{2}{*}{ DJF } & FSSTc_SOMc & -37.3244 & 31.2365 & 68.5609 & -0.0885 \\
& FSSTnc_SOMc & -37.3937 & 31.2557 & 68.6494 & \\
\multirow{2}{*}{ MAM } & FSSTc_SOMc & -34.2649 & 29.3516 & 63.6165 & 0.1211 \\
& FSSTnc_SOMc & -34.4486 & 29.0468 & 63.4954 & \\
\multirow{2}{*}{ JJA } & FSSTc_SOMc & -30.2537 & 38.485 & 68.7387 & -0.2273 \\
& FSSTnc_SOMc & -30.1896 & 38.7764 & 68.966 & \\
SON & FSSTc_SOMc & -31.8999 & 37.8514 & 69.7513 & 0.3302 \\
& FSSTnc_SOMc & -31.7621 & 37.659 & 69.4211 & \\
ANN & FSSTc_SOMc & -32.9724 & 33.2778 & 66.2502 & 0.1804 \\
& FSSTnc_SOMc & -33.0213 & 33.0485 & 66.0698 & \\
\hline
\end{tabular}

Table 6. The maximum and minimum of MMC for the control and no-carbon runs based on the SOM and fixed SST simulations. Unit is $10^{9} \mathrm{~kg} \mathrm{~s}^{-1}$.

\begin{tabular}{llcrlrl}
\hline \multirow{2}{*}{ Season } & Run & Max & Min & Run & Max & \multicolumn{1}{l}{ Min } \\
\hline \multirow{2}{*}{ DJF } & SOMc & 169.722 & -48.0686 & FSSTc_SOMc & 172.156 & -48.5415 \\
& SOMnc & 176.988 & -50.5693 & FSSTnc_SOMc & 174.94 & -49.1231 \\
\multirow{2}{*}{ MAM } & SOMc & 96.5325 & -109.138 & FSSTc_SOMc & 93.7464 & -109.393 \\
& SOMnc & 102.694 & -105.059 & FSSTnc_SOMc & 99.2619 & -104.94 \\
JJA & SOMc & 46.2061 & -232.522 & FSSTc_SOMc & 47.2821 & -228.393 \\
& SOMnc & 45.0183 & -232.265 & FSSTnc_SOMc & 45.7554 & -229.01 \\
SON & SOMc & 78.0296 & -115.919 & FSSTc_SOMc & 79.3881 & -116.175 \\
& SOMnc & 79.9538 & -122.724 & FSSTnc_SOMc & 82.0232 & -116.323 \\
ANN & SOMc & 73.8648 & -108.231 & FSSTc_SOMc & 74.8854 & -108.385 \\
& SOMnc & 75.5864 & -108.067 & FSSTnc_SOMc & 76.9408 & -106.496 \\
\hline
\end{tabular}



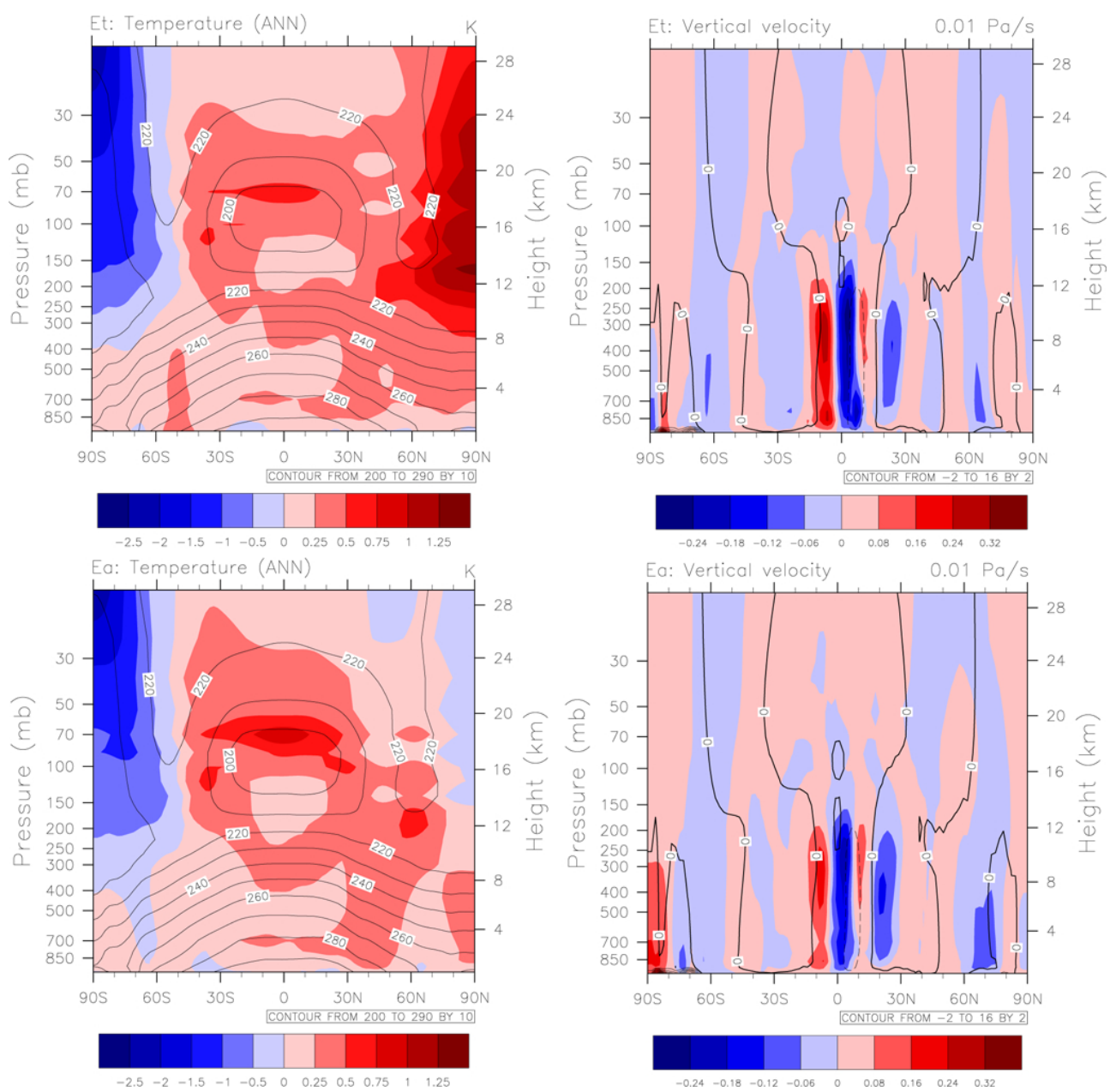

Fig. 7. Vertical profiles of zonal mean changes in temperature (left column) and omega fields (right column) for Et and Ea. Color shading denotes changes and black contour lines represent climatology based on the no-carbon run.

the Hadley cell has widened by approximately $2-5^{\circ}$ since 1979 (Hu and Fu, 2007; Fu et al., 2006; Seidel and Randel, 2007). In this study the calculated change of the Hadley cell width due to carbonaceous aerosols with and without SST feedbacks is 0.14 and $0.18^{\circ}$, respectively.

The induced changes in the MMC strength due to radiative forcing of carbonaceous aerosols is quantified by calculating the maximum and minimum of MMC. Table 6 lists the seasonal and annual means of MMC maximum and minimum values. Both SOM and the fixed SST runs show that for most seasons except summer, the maximum of MMC decreases in the run with carbon aerosols as compared to the run without carbon aerosols. In general, based on the metric of MMC maximum, the annual mean MMC strength weakens by $-2.7 \%$ and $-2.3 \%$ in the run with carbon aerosols for the SOM and the fixed SST simulations, respectively. Both ocean runs predict a decrease of MMC minimum for the spring and annual average. Our results show that on average, carbon aerosols have the effect of weakening MMC through their direct radiative effects and aerosol-induced SST effects, especially in the $\mathrm{NH}$.

\subsection{Response of zonal wind}

Figure 10 shows the Et and Ea analyses for zonal wind profiles. Only DJF and JJA profiles are included. Both Ea and Et show decreased $u$ winds near $30^{\circ} \mathrm{N}$ from $850 \mathrm{mb}$ to the highest layer and a slight increase at the regions around 50$60^{\circ} \mathrm{N}$. Quantitatively, the magnitudes of these changes are larger in Ea than Et. Thus the interactive SST effects induced by aerosol forcing have caused the opposite effects on zonal wind changes as compared to the change of zonal winds induced solely from the aerosol radiative effects. To better quantify widening of tropics, zonal mean near-surface $u$ wind was also analyzed (not shown). We found only a slight increase of width on JJA can be identified visually in the SOM runs. This result is consistent with calculation summarized in Table 4. Note that a study by Allen and Sherwood (2010) investigated the impacts of anthropogenic and natural forcings 

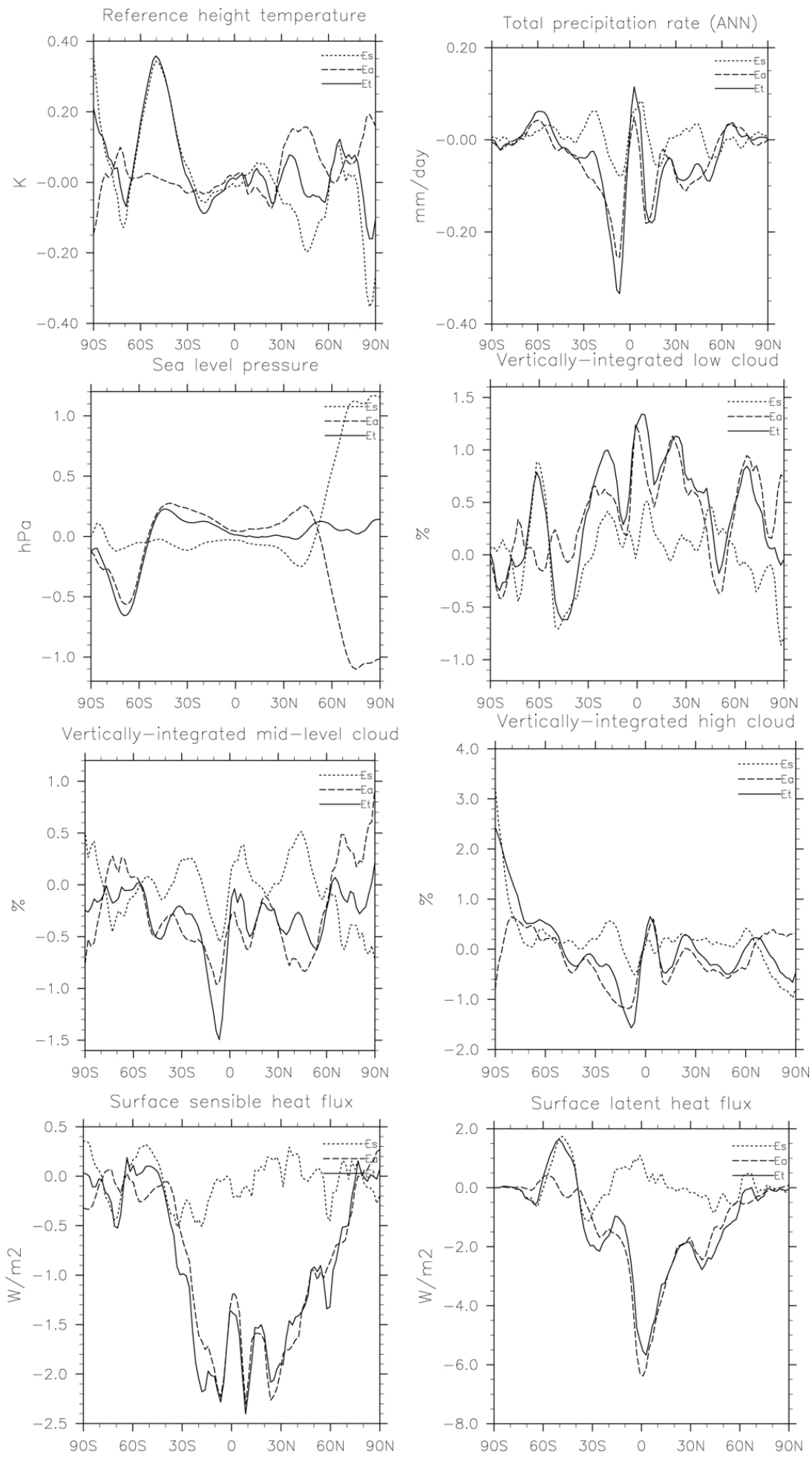

Fig. 8. Changes in zonal averages of surface air temperature; precipitation; SLP; low-, middle-, high-level cloud coverage; and sensible and latent heat flux. The unit of each variable is shown on the $y$ axis. 

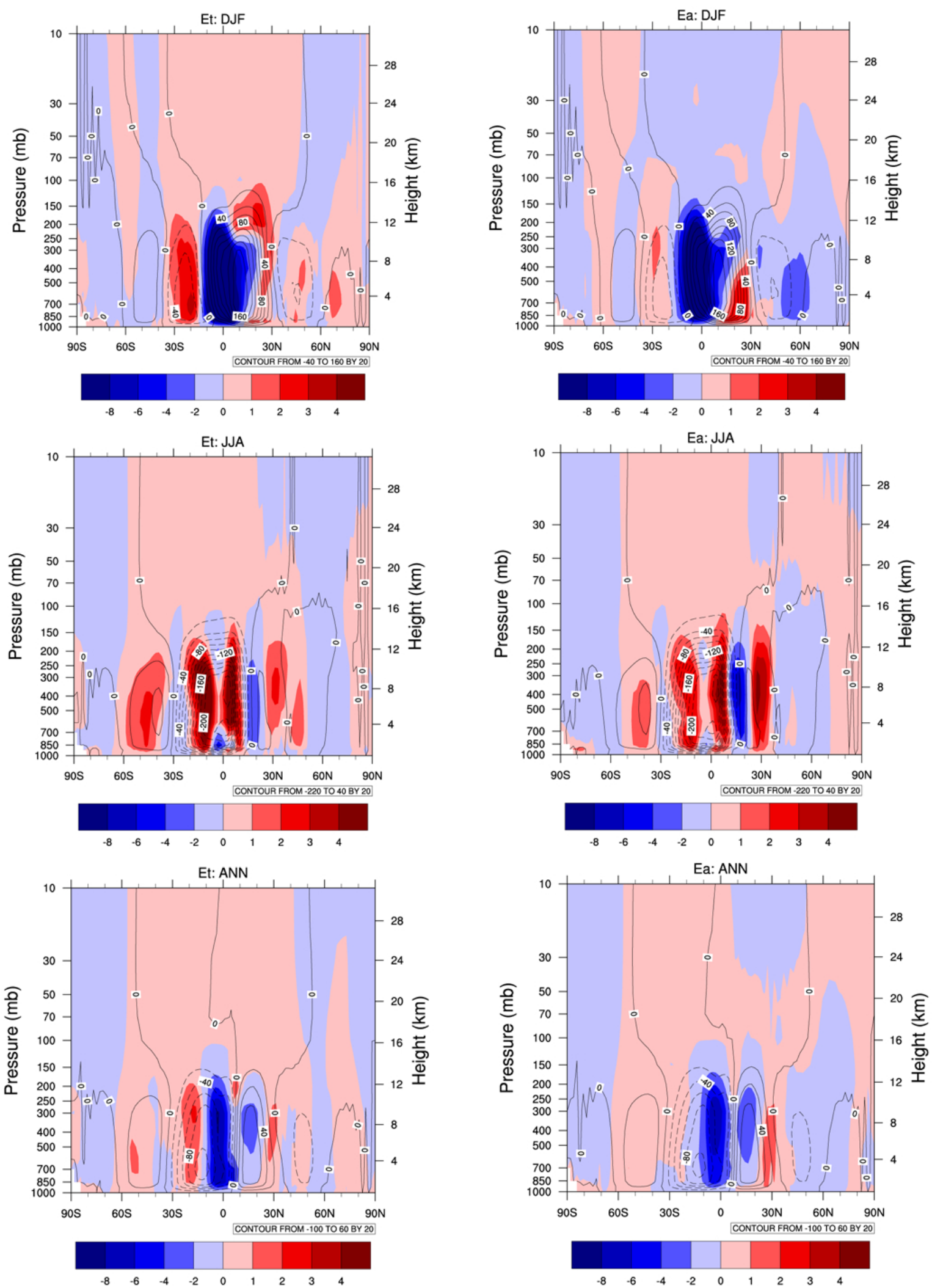

Fig. 9. Et and Ea of mean meridional circulation shown in color shades. The line contours represent climatology for the no-carbon runs. The solid lines stand for positive values of MMC and dash lines represent negative values of MMC. Unit is $10^{9} \mathrm{~kg} \mathrm{~s}^{-1}$. 

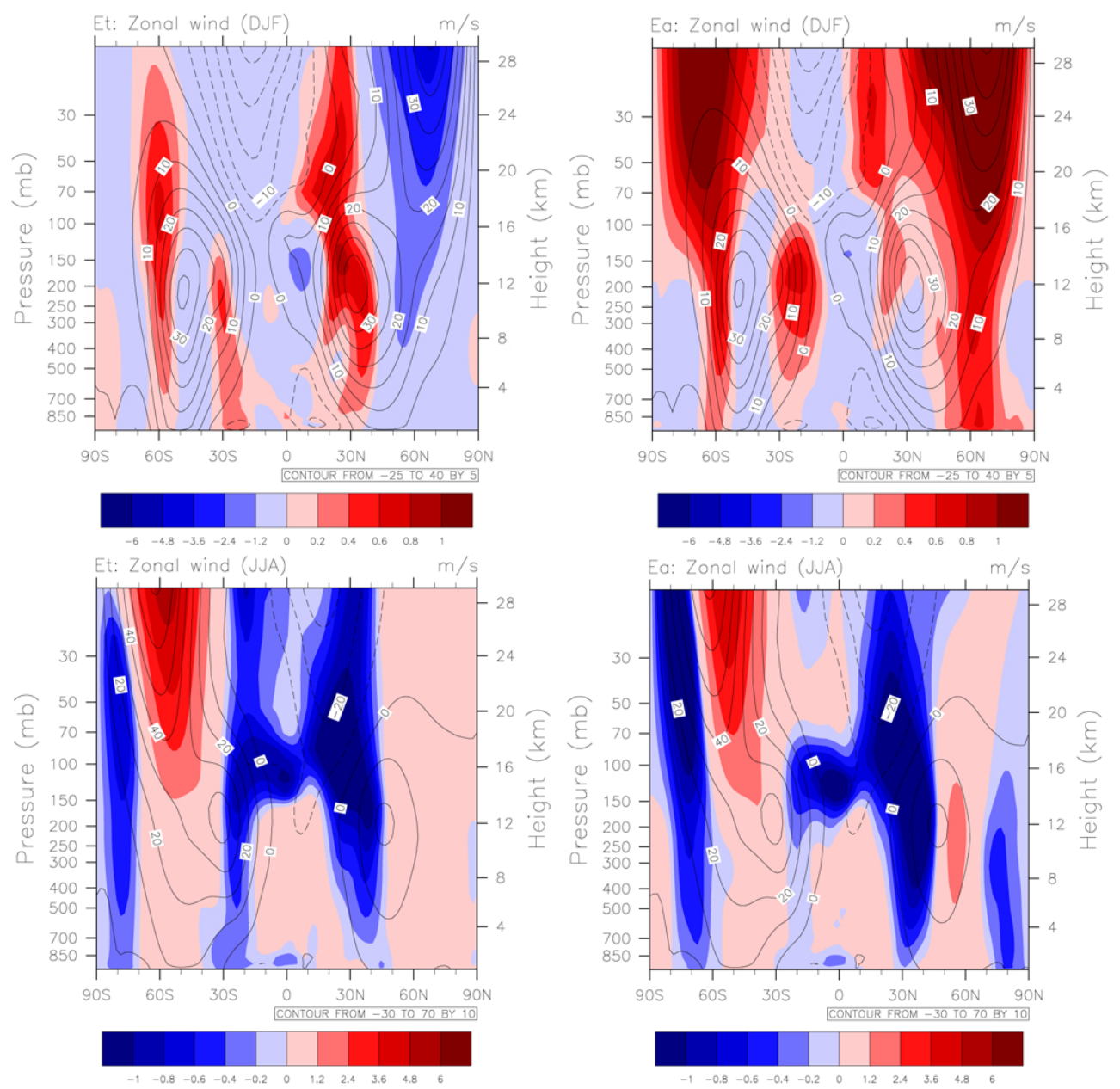

Fig. 10. Changes in zonal wind shown in color bars. The climatology is shown in contours for the no-carbon run. Unit is $\mathrm{ms}^{-}$.

on atmospheric circulations. In their results, the zonal wind changes in the fixed SST simulations are similar to the SOM runs for both patterns and absolute magnitudes. The DJF zonal wind changes in Allen and Sherwood (2010) show an increase of zonal wind around $50-60^{\circ} \mathrm{N}$ from 850 to $20 \mathrm{hPa}$ for both fixed SST and SOM anthropogenic forcing runs. In our fixed SST runs, an increase of zonal wind around 50$60^{\circ} \mathrm{N}$ is also observed. The pattern of the increase of zonal wind around $50-60^{\circ} \mathrm{N}$ for DJF is not shown in our SOM results. The increased zonal winds near the center of $\mathrm{NH}$ jet streams around $12 \mathrm{~km}$ in DJF is further enhanced when SST is allowed to respond to aerosol forcing. The coupled atmosphere-ocean model shows the opposite result of zonal wind response as compared to the fixed SST near $60^{\circ} \mathrm{N}$. This implies the interactive SST effects induced by aerosol forcing have effects on high-latitude weather systems and cause changes in zonal mean wind profiles.

\subsection{Response of radiative flux, cloud, and SST}

Figure 11 shows Et, Ea, and Es for annual mean all-sky net shortwave radiative flux at top of model (TOM) and surface. The global mean value of shortwave/longwave radiative flux change at TOM is $0.21 / 0.56 \mathrm{Wm}^{-2}$ versus $0.37 / 0.60 \mathrm{Wm}^{-2}$ for the SOM and the fixed SST runs, respectively. The global mean value of shortwave/longwave radiative flux change at the surface for the SOM runs is $-3.92 /-0.78 \mathrm{Wm}^{-2}$ and for the fixed SST runs is $-4.12 /-0.66 \mathrm{Wm}^{-2}$. There is an induced meridional gradient of the TOM shortwave radiative flux change caused by aerosol effects in Ea, with magnitude of $\sim-2 \mathrm{Wm}^{-2}$ over the northern Indian Ocean and $<6 \mathrm{Wm}^{-2}$ over southern Indian Ocean regions. Compare to the changes of precipitation shown in Fig. 5, we found the patterns of radiative flux changes at the TOM are closely related to the patterns of precipitation changes. For example, an increase of radiative flux change at TOM is associated with a decrease of precipitation. This feature can be seen in the South Indian Ocean near the east of South Africa, northwest of China extending to Europe, Gulf of Mexico, the Atlantic 

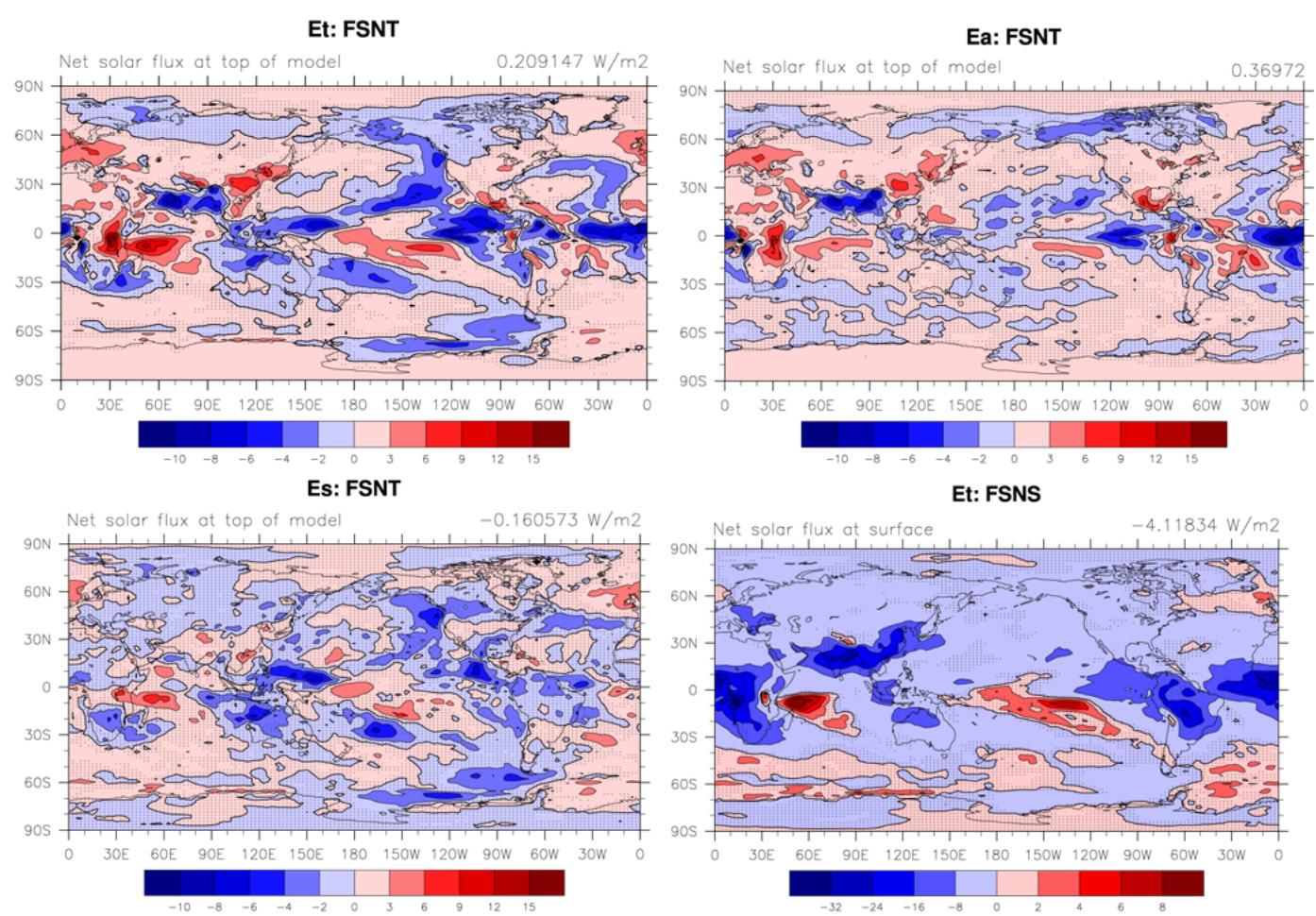

Ea: FSNS
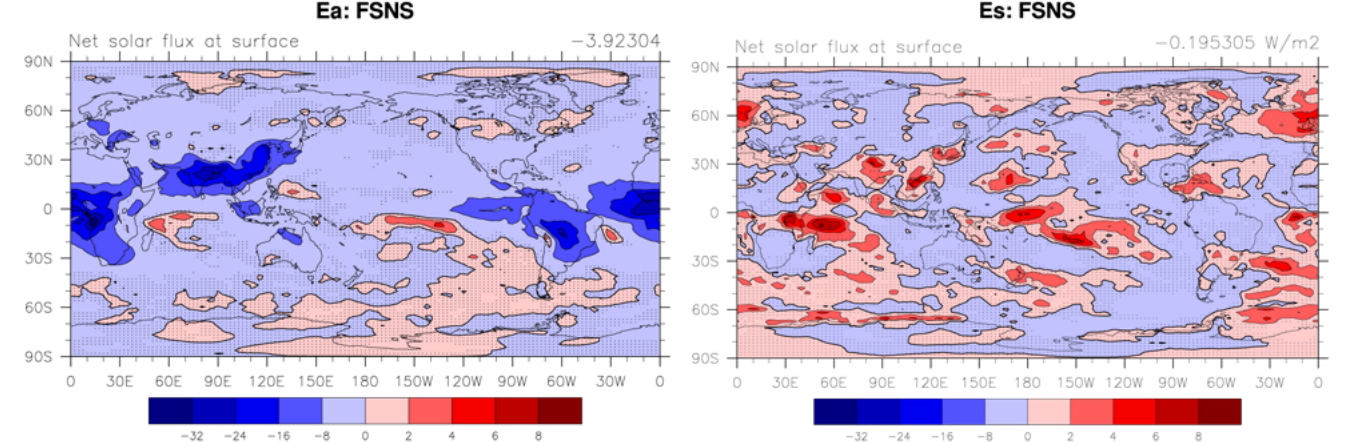

Fig. 11. Changes in annual mean all-sky shortwave radiative flux at the top of model and the surface for Et, Ea, and Es. The numbers at the right corner represent the global mean values.

Ocean near the north coast of South America, and the central Pacific in SH.

Compared to change in low-level cloud cover, cloud cover change in upper layers is more pronounced at low latitudes, especially for oceanic regions. The negative correlation between changes of precipitation and changes of radiative flux at TOM is also closely related to cloud fields (Fig. 12). The regions of negative changes of shortwave radiative fluxes at TOM are associated with positive changes of mid- and highlevel clouds. The increased cloud cover has the effects to reflect more sunlight, and thus net solar fluxes are reduced. An increase in clouds is more likely to induce more rain; thus an increase in precipitation is often predicted in those regions. To summarize, for most areas with pronounced precipitation change in the tropics $\left(20^{\circ} \mathrm{S}\right.$ to $\left.20^{\circ} \mathrm{N}\right)$, the changes from shortwave radiative fluxes (Fig. 11), precipitation (Fig. 5), and clouds (especially mid- and high-level clouds, Fig. 12) show physically consistent patterns. On global average, lowlevel cloud coverage increases by $0.54 \%$ in Et and $0.46 \%$ in Ea. Both mid- and high-level cloud coverage decreases (Table 3). One of factors in determining cloudiness response is injection height of aerosols. The increase of low-level cloud and decrease of upper level cloud is attributed to aerosols injected at the midtroposphere. Our results agree with most global model studies that showed a net increase in low-level cloud cover and decrease in upper level cloud cover (Koch and Del Genio, 2010).

The changes of net solar fluxes at the surface shown in Fig. 11 reveal a strong signal of dimming effects caused by carbonaceous aerosols (Ramanathan and Carmichael, 2008). Near the source regions with high emissions of carbonaceous aerosols, there is a relatively stronger negative radiative flux 

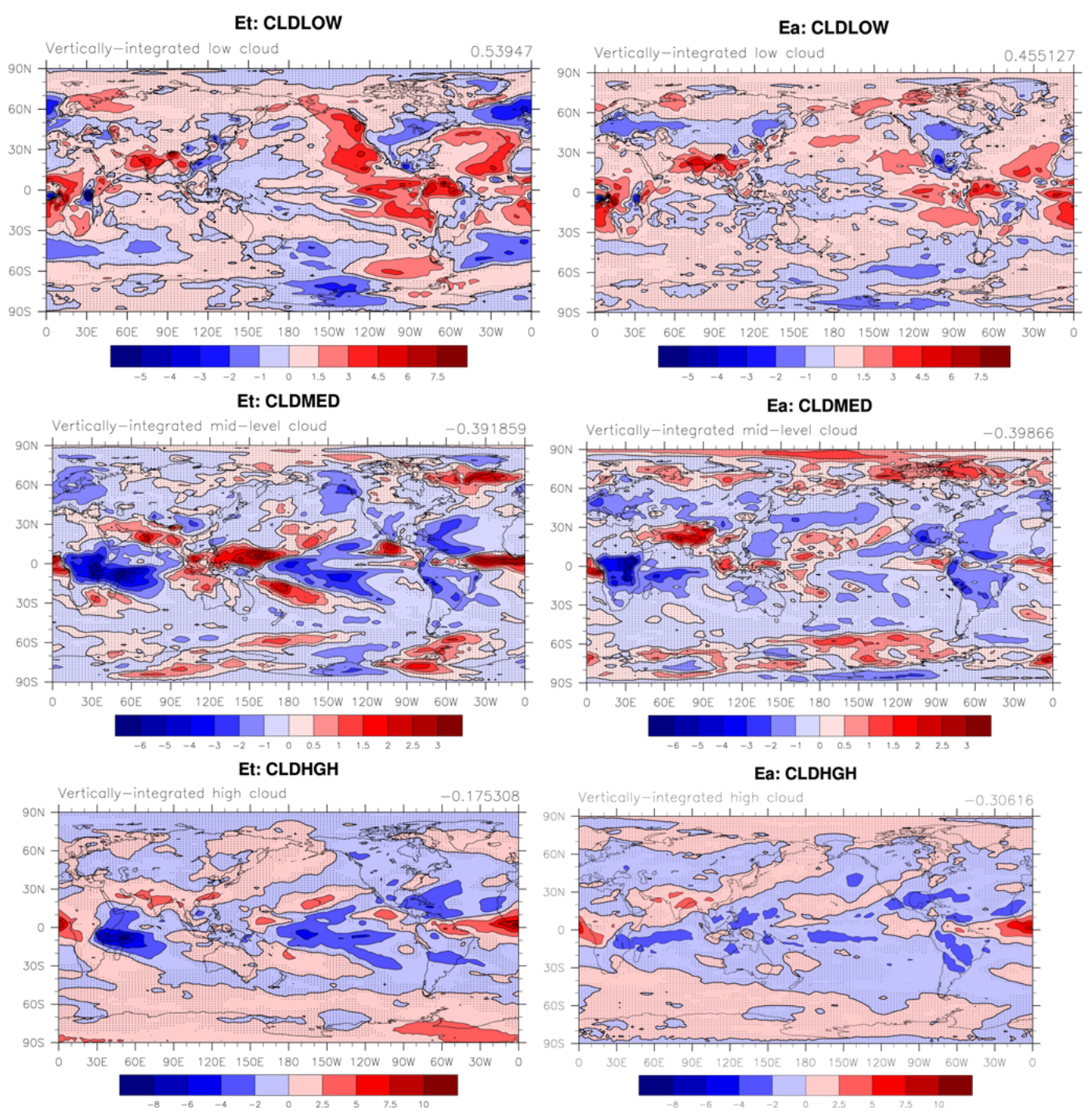

Fig. 12. Changes in annual mean low-, mid-, and high-level cloud coverage (\%).

change (i.e., cooling) at the surface. The changes of net longwave radiative fluxes at the surface in these regions also show a cooling effect, but with a much smaller magnitude (not shown). The global mean response for most radiative flux fields reveals that the global mean change from SST effects (Es) is much smaller than the global mean change induced by aerosol effects $(\mathrm{Ea})$.

Figure 3 shows the change of SST induced by radiative carbonaceous aerosol effects calculated from the two SOM runs. By allowing SST response to aerosol forcing, a cooling of SST is simulated in the northeast Pacific near the west coast of North America. A smaller but statistically significant SST cooling is also predicted in the South Pacific next to the west of South America. The reduced SST is associated with an increase of low-level cloud coverage in these areas (Fig. 12). The change of low-level cloud has important implication for future climate projections. As it has been rec- ognized for some time, feedbacks involving low-level clouds is one of the primary mechanisms that cause uncertainty in climate simulations (Clement et al., 2009).

\subsection{Analysis of moisture budget equation}

In this section, we analyze the terms in the moisture budget equation to understand the physical mechanisms that cause the change of precipitation. The vertically integrated moisture budget can be expressed as (Chou et al., 2009) 

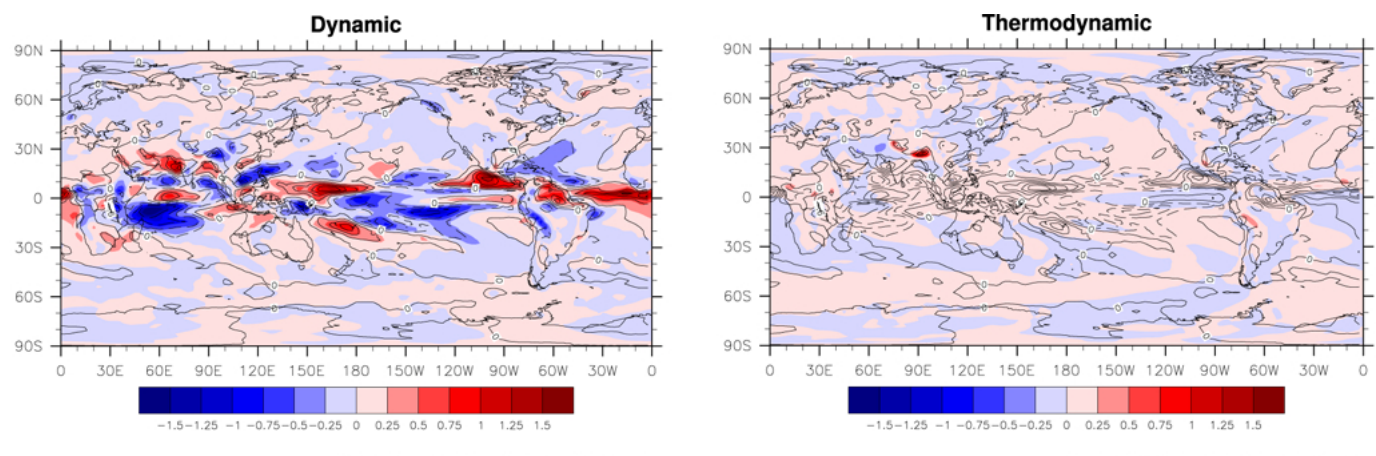

CONTOUR FROM -1.2 TO $1.2 \mathrm{BY} .3$
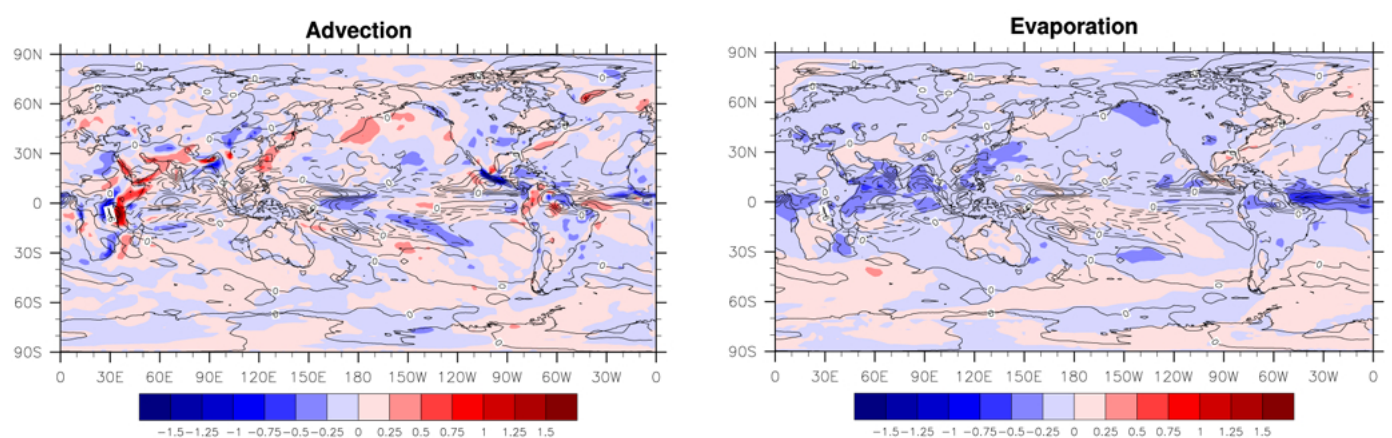

CONTOUR FROM -1.2 TO $1.2 \mathrm{BY} .3$
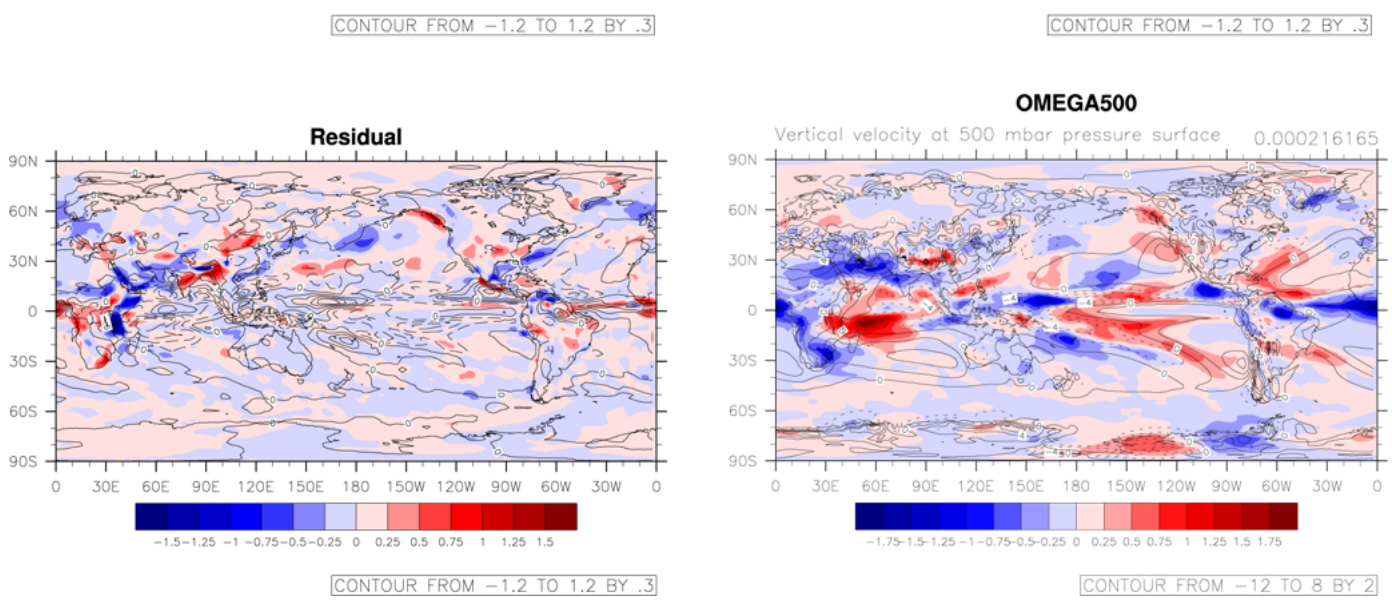

Fig. 13. Moisture budget analysis. Magnitude of each term is shown in colors and unit is $\mathrm{mm} \mathrm{day}^{-1}$. Contour lines stand for precipitation change, calculated as SOMc minus SOMnc. Solid lines denote increases of precipitation and dash lines denote decreases of precipitation. Bottom right panel shows difference of $500 \mathrm{mb}$ vertical velocity at the pressure coordinate (color shading), and the contours stand for climatology of no-carbon run. The unit is $0.01 \mathrm{~Pa} \mathrm{~s}^{-1}$.

$$
\begin{aligned}
P^{\prime} & =-g^{-1} \int_{p_{\mathrm{s}}}^{p_{\mathrm{s}}-p_{\mathrm{T}}} \bar{\omega} \frac{\partial q^{\prime}}{\partial p} \mathrm{~d} p-g^{-1} \int_{p_{\mathrm{s}}}^{p_{\mathrm{s}}-p_{\mathrm{T}}} \omega^{\prime} \frac{\partial \bar{q}}{\partial p} \mathrm{~d} p \\
& -\left(g^{-1} \int_{p_{\mathrm{s}}}^{p_{\mathrm{s}}-p_{\mathrm{T}}} v \cdot \nabla q \mathrm{~d} p\right)^{\prime}+E^{\prime}+\text { residual },
\end{aligned}
$$

where $P$ is precipitation. $\overline{()}$ denotes the climatology value, which in this study is the annual mean values based on simu- lations without carbonaceous aerosols. ( $)^{\prime}$ represents the perturbation caused by carbonaceous aerosols. $q$ is the specific humidity and $g$ is the gravity acceleration. $p_{\mathrm{s}}$ and $p_{\mathrm{T}}$ are surface pressure and top pressure at upper troposphere. $\omega$ is vertical velocity in the pressure coordinate. $v$ is horizontal velocity. $E$ denotes evaporation. The first(second) term on the right of Eq. (8) is the thermodynamic (dynamic) term, and the third (fourth) term denotes changes in horizontal moisture advection (evaporation). The last term on the right of Eq. (8) represents the moisture residual term, which includes transient and nonlinear terms (Chou et al., 2009). The vertical 

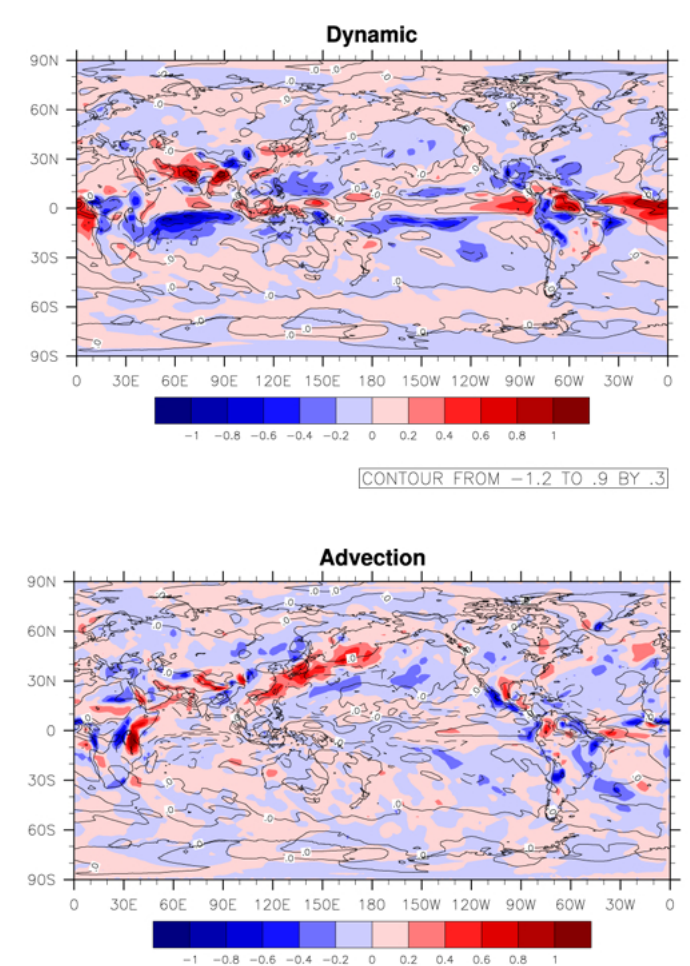

CONTOUR FROM -1.2 TO $.9 \mathrm{BY} .3$

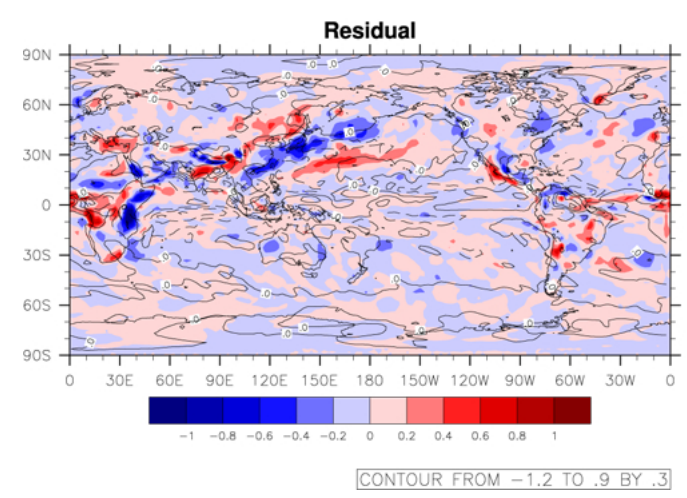

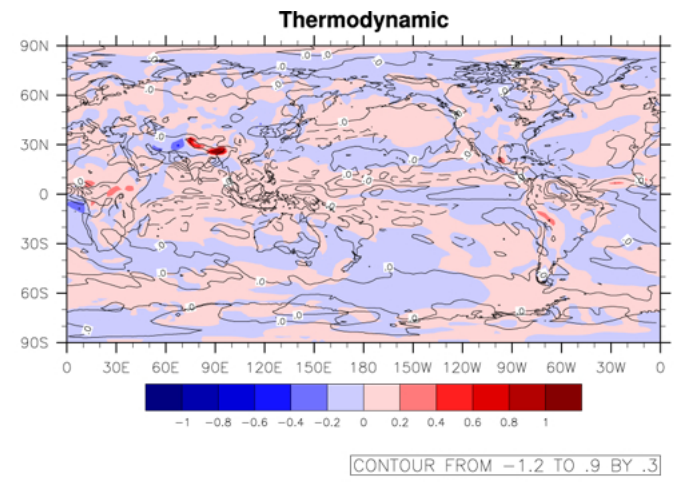

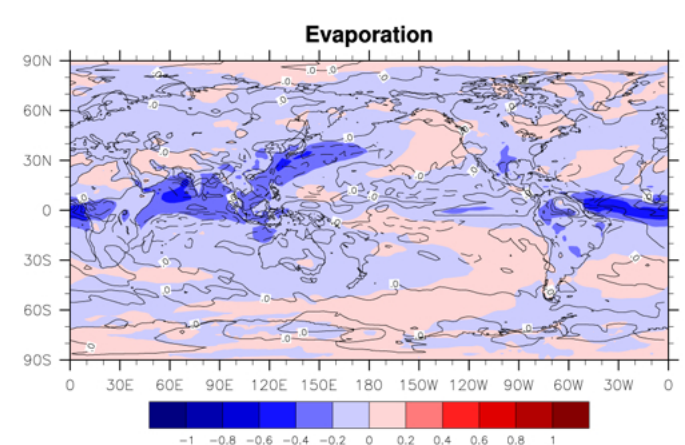

CONTOUR FROM -1.2 TO $.9 \mathrm{BY} .3$

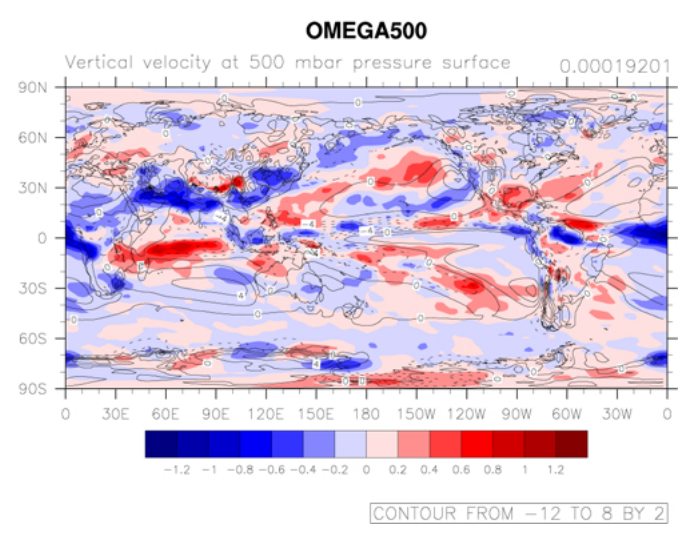

Fig. 14. Same as Fig. 13 but for the fixed SST runs (FSSTc_SOMc and FSSTnc_SOMc). Unit is mm day ${ }^{-1}$.

integration of Eq. (8) from the lowest model layer to $30 \mathrm{hPa}$ is computed in this study.

Figure 13 shows each diagnosed term in the moisture budget equation applied to annual average results from the two SOM runs. It is shown that the dynamic term has the most similar patterns with precipitation change. For example, at the places with decreased precipitation such as the South Indian Ocean, Arabian Sea, Bay of Bengal, South China Sea, and South Pacific Ocean, the dynamic term shows negative changes in those areas. For most places with increase of precipitation are associated with positive values in the diagnosed dynamic term. There are some areas with exceptions such as central India and the area near Bhutan where the dynamic term reveals opposite results with the precipitation change. Those areas are more dominated by the thermodynamic term, in which change of precipitation is mainly related to the changes in vertical moisture transport carried by the mean flow. For the area near Bhutan, the difference in horizontal moisture advection between the control and no-carbon run also contributes partially to precipitation differences. To better understand how the dynamic effect contributes to precipitation change, the change of pressure vertical velocity at $500 \mathrm{mb}$ between the runs with and without carbon aerosols is included in the bottom right plot in Fig. 13. Comparing the precipitation change and the change in pressure vertical velocity at $500 \mathrm{mb}$, we found that in most places in the 
tropics, a decrease of precipitation is associated with positive changes of pressure vertical velocity at $500 \mathrm{mb}$ (i.e., reduced upward motions). For regions of increased precipitation, an enhanced upward motion is simulated. Thus the changes of $500 \mathrm{mb}$ vertical velocity show physically consistent patterns with the dynamic effect. The corresponding analysis for the fixed SST simulations is shown in Fig. 14. Notice that the scale of each color spectrum is smaller than the analysis for the SOM runs (Fig. 13). In general, the moisture budget analysis for the fixed SST runs is qualitatively similar to the SOM runs. For most precipitation change in the tropics within $20^{\circ} \mathrm{N}$ to $20^{\circ} \mathrm{S}$, the dynamic term shows the most geographically consistent patterns with the precipitation change; that is, the sign of change is the same. The similarity of moisture budget analysis seen in the SOM and the fixed SST runs indicates that the dynamic effect induced by aerosol forcing for causing precipitation change is a robust feature, regardless of air-ocean interactions, though the magnitude of change is augmented by the feedback of coupling processes between atmosphere and ocean. Therefore, based on the moisture budget analysis, the change in precipitation due to radiative effects of carbon aerosols in this study is largely controlled by the dynamic effect. In other words, the change in the vertical moisture transport carried by the perturbed flow is the dominant mechanism for most precipitation changes simulated in the SOM and fixed SST runs.

\section{Conclusions}

The CAM3.5 was used to study effects of carbonaceous aerosols on atmospheric circulations and climate. The simulations with and without carbonaceous aerosols are conducted, and the difference between these two runs is the corresponding response induced by carbonaceous aerosols. Both SOM and fixed SST runs are used to study the effects from ocean boundary conditions. Carbon aerosols can scatter sunlight and also absorb solar energy at the same time. Both processes reduce the amount of solar radiation that reach the ground, and therefore cause a cooling at the Earth's surface. Our simulation results show a cooling is predicted in most source areas of carbon aerosols. The temperature change shows a strong warming in regions near Greenland and Iceland and a cooling in North America. These temperature responses are associated with SST feedbacks induced by direct aerosol forcing. Thus, the presence of carbon aerosols not only affects climate at local source areas but also climate at remote regions through the induced changes on energy transport processes and atmospheric circulations.

Our simulations show local aerosol forcing can largely affect tropical convection processes, which lead to changes in trade winds, meridional circulations, and precipitation. The induced changes of MMC due to carbon aerosols show a weakening of circulations near the Equator in DJF, and a strengthening is predicted at 20 to $30^{\circ} \mathrm{N}$. The quantified an- nual mean Hadley cell width change due to carbon aerosols with and without SST feedbacks is 0.14 and $0.18^{\circ}$, respectively.

The distribution of precipitation change caused by radiative aerosol forcing shows that precipitation response is more pronounced in the tropics within $20^{\circ} \mathrm{S}$ to $20^{\circ} \mathrm{N}$. In zonal average analysis, the largest decrease of precipitation is around $6^{\circ} \mathrm{S}$ of $-0.35 \mathrm{~mm} \mathrm{day}^{-1}$ for the SOM and $-0.25 \mathrm{~mm} \mathrm{day}^{-1}$ for the fixed SST runs. Both ocean boundary condition runs simulate an increase of precipitation near the Equator $\sim$ $2^{\circ} \mathrm{N}$. The simulated precipitation change in the fixed SST and SOM runs is qualitatively similar but the magnitude of change is augmented by the coupling process between atmosphere and ocean in the SOM runs. The zonal mean vertical profiles of vertical velocity changes show an increase in upward motions near the Equator in the $\mathrm{NH}$ that is associated with the peak increase of precipitation at around $2^{\circ} \mathrm{N}$.

The changes of cloud fields caused by aerosol forcing may have important implications for understanding cloud feedback processes. Our coupled atmosphere-slab-ocean-model runs simulate a decreased SST in the northeast Pacific, which is associated with an increase of low-level cloud coverage there. This phenomenon is not predicted in the fixed SST runs, and thus the induced change in SST due to external aerosol effects is the main cause for the changes of low-level clouds. Understanding changes of low-level clouds and the feedbacks they induce are crucial to constrain uncertainty of climate simulations.

We analyzed an approximated moisture budget equation based on Chou et al. (2009) to understand the physical mechanisms of precipitation changes induced by carbon aerosols. Our results showed that most regional precipitation changes are mainly dominated by the dynamic effect (i.e., the vertical moisture transport by the perturbed flow). The distributions of vertical velocity changes also show physically consistent features with the changes in precipitation.

Acknowledgements. This work was supported by Contractor Supporting Research (CSR) funding from Berkeley Lab, provided by the director, Office of Science, of the US Department of Energy under contract no. DE-AC02-05CH11231. This material is also supported by the National Science Foundation Science and Technology Center for Multiscale Modeling of Atmospheric Processes, CMMAP, managed by Colorado State University under cooperative agreement no. ATM-0425247. The National Center for Atmospheric Research is sponsored by the NSF. We would also like to acknowledge support for high-performance computing provided by NCAR's Computational and Information Systems Laboratory, sponsored by the NSF. We thank the editors for their comments and the reviewers for their suggestions, which largely improved the content of this paper.

Edited by: J. Quaas 


\section{References}

Allen, R. J. and Sherwood, S. C.: The impact of natural versus anthropogenic aerosols on atmospheric circulation in the Community Atmosphere Model, Clim. Dyn., 36, 1959-1978, doi:10.1007/s00382-010-0898-8, 2010.

Ban-Weiss, G. A., Cao, L., Bala, G., and Caldeira, K.: Dependence of climate forcing and response on the altitude of black carbon aerosols, Climate Dyn., 38, 897-911, doi:10.1007/s00382-0111052-y, 2011.

Bollasina, M. A., Ming, Y., and Ramaswamy, V.: Anthropogenic aerosols and the weakening of the South Asian summer monsoon, Science, 334, 502-505, 2011.

Chiang, J. C. H., Zebiak, S. E., and Cane, M. A.: Relative roles of elevated heating and surface temperature gradients in driving anomalous surface winds over tropical oceans, J. Aerosol Sci., 58, 1371-1394, 2001.

Chou, C., Neelin, J. D., Chen, C. A., and Tu, J. Y.: Evaluating the "rich-get-richer" mechanism in tropical precipitation change under global warming, J. Climate, 22, 1982-2005, doi:10.1175/2008JCLI2471.1, 2009.

Chung, C. E., Ramanathan, V., and Kiehl, J. T.: Effects of the South Asian absorbing haze on the Northeast Monsoon and surface-air heat exchange, J. Climate, 15, 2462-2476, 2002.

Chung, S. H. and Seinfeld, J. H.: Climate response of direct radiative forcing of anthropogenic black carbon, J. Geophys. Res., 110, D11102, doi:10.1029/2004JD005441, 2005.

Clement, A. C., Burgman, R., and Norris, J. R.: Observational and model evidence for positive low-level cloud feedback, Science, 325, 460-464, 2009.

Collins, W. D., Rasch, P. J., Eaton, B. E., Fillmore, D. W., Kiehl, J. T., Beck, T. C., and Zender, C. S.: Simulation of aerosol distributions and radiative forcing for INDOEX: Regional climate impacts, J. Geophys. Res., 107, 4664, doi:10.1029/2001JD001365, 2002.

Collins, W. D., Rasch, P. J., Boville, B. A., Hack, J. J., McCaa, J. R., Williamson, D. L., Briegleb, B. P., Bitz, C. M., Lin, S. J., and Zhang, M.: The formulation and atmospheric simulation of the community atmosphere model version 3 (CAM 3), J. Atmos. Sci., 19, 2144-2161, 2006.

Feingold, G., Jiang, H., and Harrington, J. Y.: On smoke suppression of clouds in amazonia, Geophys. Res. Lett., 32, L02804, doi:10.1029/2004GL021369, 2005.

Fu, Q., Johanson, C. M., Wallace, J. M., and Reichler, T.: Enhanced mid-latitude tropospheric warming in satellite measurements, Science, 312, 1179, doi:10.1126/science.1125566, 2006.

$\mathrm{Hu}, \mathrm{Y}$. and $\mathrm{Fu}, \mathrm{Q}$.: Observed poleward expansion of the Hadley circulation since 1979, Atmos. Chem. Phys., 7, 5229-5236, doi:10.5194/acp-7-5229-2007, 2007.

Johanson, C. M. and $\mathrm{Fu}, \mathrm{Q}$.: Hadley cell widening: Model simulations versus observations, J. Climate, 22, 2713-2725, doi:10.1175/2008JCLI2620.1, 2009.

Kalnay, E. E. A.: The NCEP/NCAR 40-year reanalysis project, 77, 437-471, 1996.
Koch, D. and Del Genio, A. D.: Black carbon semi-direct effects on cloud cover: review and synthesis, Atmos. Chem. Phys., 10, 7685-7696, doi:10.5194/acp-10-7685-2010, 2010.

Lau, K.-M. and Kim, K.-M.: Observational relationships between aerosol and Asian monsoon rainfall, and circulation, Geophys. Res. Lett., 33, L21810, doi:10.1029/2006GL027546, 2006.

Meehl, G. A., Washington, W. M., Santer, B. D., Collins, J. M. A. W. D., Hu, A., Lawrence, D. M., Teng, H., Buja, L. E., and Strand, W. G.: Climate change projections for twenty-first century and climate change commitment in the CCSM3, J. Climate, 19, 2597-2616, 2006.

Meehl, G. A., Arblaster, J. M., and Collins, W. D.: Effects of black carbon aerosols on the indian monsoon, J. Climate, 21, 28692882, 2008.

Menon, S., Hansen, J., Nazarenko, L., and Luo, Y.: Climate effects of black carbon aerosols in china and india, Science, 297, 22502253, 2002.

Ming, Y. and Ramaswamy, V.: A model investigation of aerosolinduced changes in tropical circulation, J. Climate, 24, 51255133, 2011.

Ming, Y., Ramaswamy, V., and Chen, G.: A model investigation of aerosol-induced changes in boreal winter extratropical circulation, J. Climate, 24, 6077-6091, 2011.

Ramanathan, V. and Carmichael, G.: Global and regional climate changes due to black carbon, Nat. Geosci., 1, 221-227, 2008.

Ramanathan, V., Chung, C., Kim, D., Bettge, T., Buja, L., Kiehl, J. T., Washington, W. M., Fu, Q., Sikka, D. R., and Wild, M.: Atmospheric brown clouds: Impacts on South Asian climate and hydrological cycle, P. Natl. Acad. Sci. USA, 102, 5326-5333, 2005.

Rasch, P. J., Mahowald, N. M., and Eaton, B. E.: Representations of transport, convection, and the hydrologic cycle in chemical transport models: implications for the modeling of short-lived and soluble species, J. Geophys. Res., 102, 28127-28138, 1997.

Rasch, P. J., Collins, W. D., and Eaton, B. E.: Understanding the Indian Ocean Experiment (INDOEX) aerosol distributions with an aerosol assimilation, J. Geophys. Res., 106, 7337-7356, 2001.

Seidel, D. J. and Randel, W. J.: Recent widening of the tropical belt: Evidence from tropopause observations, J. Geophys. Res., 112, D20113, doi:10.1029/2007JD008861, 2007.

Stowe, L. L., Ignatov, A. M., and Singh, R. R.: Development, validation, and potential enhancements to the second-generation operational aerosol product at the National Environmental Satellite, Data, and Information Service of the National Oceanic and Atmospheric Administration, J. Geophys. Res., 102, 16923-16934, 1997.

Wang, C.: A modeling study on the climate impacts of black carbon aerosols, J. Geophys. Res., 109, D03106, doi:10.1029/2003JD004084, 2004.

Zwiers, F. W. and von Storch, H.: Taking serial correlation into account in tests of the mean, J. Climate, 8, 336-351, 1995. 